\title{
Effect of Regulatory Constraints on Fund Performance: New Evidence from UCITS Hedge Funds
}

\author{
JUHA JOENVÄÄRÄ and ROBERT KOSOWSKI
}

This version: 15 September 2015

\begin{abstract}
We economically motivate and then test a range of hypotheses regarding performance and risk differences between UCITS-compliant and other hedge funds. The latter exhibit more suspicious return patterns than do absolute return UCITS (ARUs), but ARUs exhibit higher levels of operational risk. We find evidence of a strong liquidity premium: hedge funds offer investors less liquidity than do ARUs yet exhibit better risk-adjusted performance. Our findings are substantially unchanged under various robustness tests and adjustments for possible selection bias. The liquidity premium for ARUs and their lack of performance persistence have implications for both investors and policy makers.
\end{abstract}

JEL Classifications: G11, G12, G23

Keywords: hedge fund performance, mutual fund performance, managerial skill, regulation 


\section{Introduction}

One goal of financial regulation is to protect investors by ensuring that markets are fair and that fraudulent activities are minimized. Despite calls in 2009 by the G20 (an international finance minister and central bank governor forum) for coordinated international financial regulation following the 2007-2008 financial crisis, financial regulation continues to vary widely by country. With regard to alternative investment funds, regulatory responses - for example, the US Dodd-Frank Act and the European Union's AIFMD ${ }^{1}$ - also display significant geographic differences with regard to liquidity requirements, remuneration rules, and risk limits. Such differences almost certainly have a welfare impact by way of the resulting performance and risk differences among alternative investment funds, which are held by pension funds, sovereign wealth funds, and other investors. A particular type of EU investment fund regulation is UCITS, ${ }^{2}$ which has global implications because it involves unique and testable restrictions (e.g., the effect of liquidity terms on fund performance) intended to enhance investor protection. We use UCITS restrictions on hedge funds as a natural testing ground for assessing several hypotheses concerning hedge fund performance while carefully adjusting for selection bias.

The UCITS funds universe is economically important, and UCITS funds are recognized - and can be marketed - in 75 countries worldwide. The assets under management (AuM) of UCITS funds amount to some $\$ 8$ trillion, which is comparable to the US mutual fund industry's $\$ 11.6$ trillion. $^{3}$ Outside the United States, UCITS funds account for more than half of fund assets worldwide, and about three fourths of the funds publicly sold in Asia are UCITS funds. ${ }^{4}$ The impact of UCITS is felt also by non-European investors and managers. For instance, Paulson \& Co. (a renowned US hedge fund management firm) launched a UCITS version of its flagship offshore hedge fund with Deutsche Bank in $2010 .^{5}$

Alternative investment fund managers are increasingly deciding to implement alternative strategies through more regulated vehicles so that they can gain access to the assets of retail and institutional investors, which typically prefer funds that are more regulated and more liquid. The Dodd-Frank requirement for hedge funds to register with the US Securities and Exchange Commission

\footnotetext{
${ }^{1}$ The objective of this Alternative Investment Fund Manager Directive is to create a comprehensive and secure framework for the supervision and prudential oversight of such managers in the EU.

${ }^{2}$ The acronym UCITS stands for Undertakings for Collective Investment in Transferable Securities, which is the European harmonized and regulated fund product. It can be sold on a cross-border basis within the European Union based solely on its authorization in a single EU member state. See Appendix A for additional details about UCITS.

${ }^{3}$ See the ICI (2012) factbook and http://www.efama.org.

${ }^{4}$ Carne Group, "UCITS Guide for Alternative Managers," 30 June 2012.

${ }^{5}$ Sam Jones, “Investment management: Europe’s changing face," Financial Times, 10 May 2012.
} 
(SEC) has increased the popularity of liquid alternatives in the United States, as illustrated by the following quote from the Financial Times: "An American version of the 'hedge-fund lite' Ucits funds popular in Europe - so-called liquid alternative funds, registered under the Investment Company Act of 1940 - is in vogue."

Yet packaging hedge fund strategies in a traditional format is far from straightforward, and it raises many challenges both for managers and for the regulatory format's brand. It is crucial to determine whether structuring hedge fund strategies through vehicles that are more regulated will yield the same level of returns or rather compromise those strategies - given the constraints imposed by regulations: investment restrictions, liquidity requirements, operational requirements, and risk limits. ${ }^{7}$

What are the main differences between regulation governing hedge funds and UCITS funds? First, to enhance transparency and protect investors against misreporting, regulation imposes tight net asset value (NAV) reporting requirements and valuation rules for UCITS-compliant funds while offshore hedge funds are not subject to such requirements. Second, to address the operational risks that may emanate from organizational deficiencies or conflicts of interest the UCITS directive requires UCITS managers to produce and maintain on an on-going basis a so-called Risk Management Policy ('RMP') document and the directive imposes strict requirements for organizational and internal controls and for conflicts of interest. Although all investment managers will have to identify and effectively manage conflicts of interest in the design and implementation of their risk management frameworks, hedge funds are not required to produce a RMP document. Third, several UCITS rules constrain the investment opportunity set and possible portfolio weights. The concepts of liquidity and transferability drive asset selection and portfolio construction for a UCITS and UCITS rules limit the investments of UCITS to "eligible assets" and preclude physical short-selling. ${ }^{8}$ Fourth, UCITS funds are required to have a separate risk management function and are subject to leverage limits, and valueat-risk limits, requirements that do not explicitly apply to equivalent hedge funds. Fifth, as mentioned earlier, UCITS funds have to provide bi-weekly liquidity while hedge funds do not have any restrictions regarding notice, redemption or lockup periods.

\footnotetext{
${ }^{6}$ Ellen Kelleher, "Investor demand drives US move to alternative mutual funds," Financial Times, 1 December 2013.

${ }^{7}$ Hedge funds have an absolute return objective - namely, achieving returns that are uncorrelated with the market (Ineichen 2002). The absolute return objective implies that risk reduction techniques (e.g., long-short strategies and taking positions in derivatives) are used to reduce benchmark exposure levels.

${ }^{8}$ Broadly speaking transferable and liquid assets are considered eligible but there are some exceptions. For reasons of space we report details about asset eligibility in Appendix.
} 
The above regulatory comparison shows that, on the one hand, the UCITS directive imposes restrictions on alternative investment fund managers that in some respects are even more stringent than those imposed by SEC regulation on hedge fund managers. On the other hand, UCITS rules are less stringent than those that must be followed in the United States by so-called ' 40 Act alternative funds. These funds (which are governed by the US Investment Company Act of 1940) must provide daily liquidity, cannot exceed 33\% gross leverage, and are not allowed to charge performance-based fees. In contrast, UCITS funds need provide liquidity just only every other week, can use higher leverage, and can charge performance-based fees. The obvious implication is that UCITS-compliant hedge funds may exhibit performance and risk characteristics that differ from those of other hedge funds. In this paper, we focus on UCITS (rather than ' 40 Act) fund rules because they are less stringent and so may facilitate our replication of the strategies employed by hedge funds. We gather data on UCITScompliant hedge funds, also known as absolute return UCITS, and compare them with data from a large global hedge fund database. Thus we distinguish between these absolute return UCITS (abbreviated ARUs) and other, non-UCITS hedge funds abbreviated HFs, for expositional convenience, even though UCITS funds are also hedge funds). The current size of the ARU universe is estimated to be $\$ 230$ billion, or about $12 \%$ of the $\$ 1,981$ billion in global hedge fund assets; note that the number of ARU funds grew fivefold over our 2003-2013.

The geographically disparate hedge fund regulation reviewed above enables several testable implications. We start by focusing on returns misreporting and asset illiquidity. The prior literature (e.g., Agarwal, Daniel, and Naik 2011; Bollen and Pool 2008, 2009) documents that hedge funds' reported returns are sometimes suspicious. Regulation imposes tight net asset value (NAV) reporting requirements and valuation rules for UCITS-compliant funds. These requirements are likely to make return misreporting more difficult. Therefore, our Misvaluation Hypothesis states that UCITS funds should engage less in return management than do hedge funds. We use a set of "red flags" proposed by Bollen and Pool (2012) to establish that hedge funds' reported returns exhibit relatively more suspicious patterns. ${ }^{9}$ So in terms of accurate valuations, our results are consistent with interpreting UCITS regulation as being protective of investors and thus as having achieved one of its goals.

Second, our Operational Risk Hypothesis is that such risk should be lower for UCITScompliant funds than for other, presumably less transparent hedge funds. The intuition is that the UCITS directive imposes strict requirements for organizational and internal controls and for conflicts

\footnotetext{
${ }^{9} \mathrm{We}$ carry out a range of robustness tests to disentangle returns misreporting from asset illiquidity in this context.
} 
of interest. To test this hypothesis and measure operational risk, we follow the literature initiated by Brown, Goetzmann, Liang, and Schwarz $(2008,2009)$ and use information revealed in the Forms ADV that funds must submit to the SEC. Given that ARUs are domiciled in EU member countries and are thus are less likely reporting to US-based regulators and filing Forms ADV, we control carefully for the potential effect of selection bias by means of the Heckman correction. We discover that UCITS regulation does not, in fact, reduce operational risk; that is, we find in a univariate setting that ARUs are actually more exposed to operational risk measures. In order to understand this unexpected finding, we investigate further the sources of operational risk. We find that ARUs typically have more possible conflicts of interest than do HFs. In particular, ARUs exhibit more external conflicts of interest in the form of close relationships with banks and brokers. Furthermore, when we model in a multivariate setting whether UCITS-compliant funds have more "problems" or past violations, we find an insignificant relation between UCITS structure and past violations after controlling for the role played by our indicator variables for conflicts of interest. Thus, once we include control variables, UCITScompliant funds do not have less operational risk than other hedge funds, which suggests that tighter regulation does not mitigate operational risk concerns. Our finding regarding the role of variables related to external conflicts of interest may simply reflect differences in the financial market structure of Europe versus the US, since most fund management companies are based in either of these two. Fund management companies are more intertwined with (universal) banks in Europe, which creates positive answers to the question of potential conflicts of interest.

Third, motivated by UCITS restrictions regarding eligible assets, short-selling restrictions and diversification requirements, as part of our Performance Hypothesis, we hypothesize that ARUs exhibit lower risk-adjusted returns than HFs. The UCITS directive specifies which assets are deemed eligible assets and also specifies diversification requirements. Measuring the risk-return trade-off is a complex issue; hence we employ several different metrics to assess tail risk and volatility (Patton 2009) while controlling for the effects of serial correlation in fund returns (cf. Getmansky, Lo, and Makarov 2004). Consistent with the prediction of this hypothesis, we find that UCITS-compliant funds generally generate lower risk-adjusted performance. Our results suggest that the restrictions on the investment opportunity set have an economically and statistically significant effect on the risk-adjusted performance of ARUs compared to HFs. A potential concern when comparing ARUs to HFs is selection bias, which may arise from hedge fund management companies launching UCITS share classes only for liquid hedge funds. We show that our results are not affected by selection bias by 
carrying out a Heckman adjustment.

Third, we formulate the Risk Hypothesis based on UCITS' rules that impose limits on value-atrisk and leverage and that mandate a separate risk management function. Our Risk Hypothesis states that ARUs exhibit lower risk than HFs. We find that ARUs exhibit more systematic risk, especially in terms of equity market exposure, than do other hedge funds. This result is consistent with the hurdles encountered when transporting hedge fund techniques to the UCITS universe. Because UCITS funds face restrictions regarding the use of derivatives and short-selling to hedge market risks, their consequent reduced flexibility may well make ARU returns more cyclical than those of HFs. Our results therefore suggest that, even though UCITS regulation puts strong emphasis on protecting investors from market risk, hedge funds that are less regulated seem to have internal controls that discourage them from taking excessive risk. ${ }^{10}$

Liquidity is one of the pillars of UCITS regulation, and the asset pricing literature has identified liquidity premia in many markets; these considerations lead to our Liquidity Restrictions Hypothesis. According to the UCITS directive, funds must manage all aspects of liquidity risk and must provide redemption facilities to their clients at least twice a month. In contrast, hedge funds are not subject to such tight regulation. Hence our hypothesis posits that ARUs deliver lower average performance than funds with strict share restrictions, which are able to earn a liquidity premium for holding less liquid assets (Amihud and Mendelson 1986; Pastor and Stambaugh 2003).

Our findings have policy implications and raise questions about the resulting welfare effects and an acceptable liquidity-performance trade-off. Although UCITS-compliant hedge funds underperform other hedge funds on average, the performance of these two groups converges when we compare subsets of the two fund types that are matched in terms of liquidity (i.e., share restrictions). So that we can better understand the economic mechanism that underlies investor-level share restrictions helping funds manage their portfolios more efficiently, we investigate whether leverage and margin constraints are less binding for funds that impose tight share restrictions. We find that hedge funds with long redemption periods have more exposure to the Frazzini and Pedersen (2014) betting-against-beta factor, whereas funds providing generous liquidity terms (e.g., ARUs) do not have significant loadings on that factor. This result is consistent with the interpretation that more liquid funds are more leverage constrained and therefore encounter more obstacles to investing in low-beta assets, which (according to Frazzini and Pedersen) tend to have high risk-adjusted returns.

${ }^{10}$ Cassar and Gerakos (2010) document evidence suggesting that internal controls are stronger in offshore hedge funds that have potentially higher agency costs as well as limited legal redress for fraud and financial misstatements. 
A possible criticism of our analysis so far is that, we are not comparing equivalent funds. Thus our baseline analysis, which compares an ARU fund from management company A with an HF from management company B, may be comparing "apples and oranges". By matching funds within the same management companies or the fund managers that simultaneously manage UCITS-compliant funds and hedge funds, we address the potential selection bias explicitly and to confirm that the lower performance of UCITS-compliant funds is due to restrictions - not lower fund manager skills. In robustness tests we carefully match, within management companies, the closest possible UCITS and non-UCITS fund pairs. We then use information on fund manager names to investigate whether our results hold even for managers that run UCITS-compliant and other hedge funds side by side. Using data obtained from the EurekaHedge database, we detect 276 side-by-side management cases involving 138 UCITS-compliant funds and 164 hedge funds. ${ }^{11}$ After controlling for firm-level effects and for effects related to manager skill, we find that UCITS restrictions play an important role. The difference in risk-adjusted returns to UCITS versus non-UCITS funds can be explained by differences in liquidity and leverage. In this way, we uncover a strong performance-liquidity trade-off as well as evidence of less binding leverage constraints - even after restricting our analysis to matched pairs of HFs and ARUs within the same management company and managers that simultaneously run UCITS-compliant funds and hedge funds.

Average performance differences are important from a general economic perspective, but performance persistence is more important in investors' perspective. Thus we are led to formulate our Persistence Hypothesis. The ARU universe is a fertile setting in which test whether performance persists and whether this persistence could be exploited in practice. There is theoretical and empirical evidence suggesting that the transparency required by regulatory rules may be harmful to UCITS investors. Glode and Green (2011) show theoretically that the performance persistence of hedge funds can be explained by the desire for secrecy. Such persistence may not be due entirely to skill, and it could result from techniques or strategies of which other managers are not aware. Their model's predictions are supported by Agarwal, Jiang, Tang, and Wang (2013), who document that hedge funds' confidential holdings are associated with superior performance. Investors in ARUs could (at least in principle) use the bi-weekly regulatory liquidity requirement to rebalance their portfolios on a monthly basis. However, our empirical results indicate that there are limits to the ability of investors to exploit this superior liquidity because ARUs exhibit less performance persistence than some other hedge

\footnotetext{
${ }^{11}$ Size of our sample is comparable to Nohel, Wang and Zheng (2010) that document 344 side-by-side management cases involving 693 mutual funds and 538 hedge funds.
} 
funds.

This paper sheds light on the debate over the costs and benefits of increased financial regulation. Given that such regulation is intended to protect investors, one of our main contributions to this debate is quantifying the cost of regulation and liquidity requirements. Estimates based on our data show that the indirect cost of UCITS regulation is around $2 \%$ per annum in terms of risk-adjusted returns. Because there is evidence of a substantial liquidity premium in alternative investment funds, policy makers should carefully consider the effect of higher liquidity requirements on the returns that alternative investment funds can be expected to generate. And since institutional investors (e.g., pension funds) are one of the largest groups of hedge fund investors, such requirements ultimately affect the growth of pension assets in Europe and other countries where ARU funds can be marketed. Similarly, the lack of performance persistence among ARUs should caution retail and institutional hedge fund investors against "returns chasing".

Our paper is related to four main streams of the literature. First, there is an extensive empirical asset pricing literature that addresses the effect of geography on asset price performance. ${ }^{12}$ Included in this stream are papers on the effect of domicile on hedge fund performance, but we are not aware of any paper that has examined the effect of UCITS restrictions on ARU performance.

Second, the effect of share restrictions on hedge fund performance has been studied by several authors. ${ }^{13}$ However, none of these studies examine the liquidity terms of ARUs or the effect of any such terms on their relative performance, and none have compared ARU performance persistence as compared with hedge funds that feature less stringent liquidity terms. ${ }^{14}$

Third, there is a growing literature on hedged mutual funds and UCITS funds. Agarwal, Boyson, and Naik (2009) compare the performance of hedged mutual funds to traditional mutual funds, whereas our focus is on UCITS and non-UCITS hedge funds because these two groups are more likely to allow alternative investment strategies. ${ }^{15}$ In comparison with our research, earlier studies of UCITS funds (Stefanini, Derossi, Meoli, and Vismara 2010; Tuchschmid, Wallerstein, and Zanolin 2010; Darolles 2011) use smaller samples of UCITS hedge funds and do not analyze the effect of UCITS restrictions on suspicious returns, operational risk, performance, or performance persistence.

\footnotetext{
${ }^{12}$ See, for example, Coval and Moskowitz (2001), Malloy (2005), Teo (2010 and Aragon, Liang, and Park (2013).

${ }^{13}$ See Getmansky, Lo, and Makarov (2004), Agarwal, Daniel, and Naik (2009), Teo (2010), Ding, Getmansky, Liang, and Wermers (2008), Cao, Chen, Liang, and Lo (2013), and Cao, Farnsworth, Liang, and Lo (2013).

${ }^{14}$ Amihud, Mendelson, and Pederson (2013) provide a good summary of the market liquidity literature.

${ }^{15}$ Other related studies include Cici, Gibson, and Moussawi (2010), Nohel, Wang and Zheng (2010) and Deuskar, Pollet, Wang, and Zheng (2011).
} 
Fourth, our work utilizes the notions of operational risk and suspicious return flags as developed in earlier papers. Those papers include Brown, Goetzmann, Liang, and Schwartz (2008, 2009, 2012), Bollen and Pool (2008, 2009, 2012), and Cassar and Gerakos (2010, 2011). We are the first to apply these ideas to the economically important group of ARUs and to compare ARUs with HFs.

The rest of the paper proceeds as follows. Section 2 reviews the regulatory restrictions imposed on UCITS funds and motivates the resulting testable hypotheses. Section 3 describes the HF and ARU universe, and Section 4 summarizes the empirical results on differences in operational risk between these two fund types. Section 5 focuses on the effects of fund domicile, liquidity, and leverage constraints on fund performance and risk. Section 6 reports results on performance persistence toward the end of answering whether investors could, in practice, exploit the superior liquidity of ARUs. We conclude in Section 7.

\section{UCITS Regulatory Restrictions and Testable Hypotheses}

As mentioned in Section 1, there are relatively few academic studies of UCITS mutual funds and ARUs despite their economic importance. However, there are hundreds of papers on the US mutual fund universe, which is comparable in size to the UCITS universe. So we begin by providing some background on UCITS funds before motivating our hypotheses. The UCITS directive was implemented by the EU in 1985 with the aims of facilitating cross-border markets in investment funds and maintaining a high level of investor protection. The directive was aimed at regulating the organization and oversight of UCITS funds; it imposed constraints concerning diversification, liquidity, derivatives, and use of leverage. Appendix A summarizes the evolvement of UCITS regulation.

We focus on comparing absolute return UCITS funds (ARUs) and other hedge funds (HFs), including offshore hedge funds, US onshore hedge funds, and other European onshore hedge funds.

What are the main differences between regulation governing hedge funds and ARUs? We highlight five main differences and then motivate a set of testable hypotheses based on the differences in regulation.

First, to enhance transparency and protect investors against misreporting, UCITS regulation imposes tight net asset value (NAV) reporting requirements and valuation rules for UCITS-compliant funds while off-shore hedge funds are not subject to such requirements. These requirements are likely to make return misreporting more difficult. The UCITS fund format requires funds to report net asset 
valuations on a daily basis. ${ }^{16}$ An outside firm may be appointed to undertake these valuations, but if they are performed internally then the process must be independent of portfolio management per se in order to avoid conflicts of interest.

Motivated by the findings of Agarwal, Daniel, and Naik (2011) and of Bollen and Pool (2008, 2009) that hedge funds misreport or "manage" their returns, our Misvaluation Hypothesis states that UCITS funds engage less (than do HFs) in return management. We test this claim by constructing a set of indicators proposed by Bollen and Pool (2012) to detect suspicious patterns in reported fund returns. It is worth constructing a large set of proxies owing to the challenges inherent in differentiating between asset illiquidity and returns misreporting. After all, Casser and Gerakos (2011) offer evidence suggesting that asset illiquidity is a major factor driving the anomalous properties of self-reported hedge fund returns, and Jorion and Schwarz (2014) show that incentive fees can mechanistically create discontinuity or a kink in the distribution of net returns. ${ }^{17}$

Second, to address the operational risks that could emanate from organizational deficiencies or conflicts of interest the UCITS directive requires ARU managers to produce and maintain on an ongoing basis a so-called Risk Management Policy ('RMP') document and the directive imposes strict requirements for organizational and internal controls and for conflicts of interest. Although, in principle, all investment managers have to identify and effectively manage conflicts of interest in the design and implementation of their risk management framework, hedge funds are generally not required to produce an equivalent of the RMP document.

According to the UCITS IV directive and European Securities and Markets Authority guidelines, all risks that could be material to the fund should be properly addressed by the management company in the RMP document. A fund's policy should address its exposure to market risks, liquidity risks, counterparty risks, and all other risks - including operational risk - that might be material to each UCITS it manages. Given this explicit focus on risk management and operational risk the question arises of whether the UCITS directive succeeds in reducing operational risk for ARUs compared to other hedge funds.

Following discovery of the Madoff Ponzi scheme, operational risk has been of special concern to investors, regulators, and academics (see, e.g., Brown, Goetzmann, Liang, and Schwarz 2008, 2009,

\footnotetext{
${ }^{16}$ Generally speaking, the latest official market closing prices must be used when valuing publicly traded securities; when those are not available, the "fair market value" should be used. Rules require that UCITS funds must establish valuation procedures for derivatives that are of an appropriate level of complexity and must disclose those procedures to investors. ${ }^{17}$ In a separate hypothesis we examine the effect of differences in liquidity requirements on fund performance below.
} 
2012). It is interesting that one of the Madoff feeder funds, LuxAlpha, was a UCITS-regulated fund. Was this case an exception? Do ARUs actually have lower operational risk than hedge funds?

To discover whether or not UCITS management companies are better than others at managing operational risk, we follow Brown, Goetzmann, Liang, and Schwarz $(2008,2009)$ and construct a set of operational risk measures using the information revealed in Form ADV filings. Doing so allows us to test the implications of the "organization directive", which spells out the requirements for organizational and internal control and stipulates procedures for addressing conflicts of interest. Given the focus of this directive, our Operational Risk Hypothesis predicts that, as compared with less regulated hedge funds, UCITS funds should have lower levels of operational risk and fewer conflicts of interest. That being said, Cassar and Gerakos (2010) use a sample of due diligence reports to document that internal controls are stronger in offshore hedge funds that face potentially higher agency costs and have limited legal redress against fraud or financial misstatements. So it remains an open question whether tighter regulation can protect investors from operational risk - a question that we examine in this paper.

Third, several UCITS rules related to eligible assets and disallowed strategies constrain the investment opportunity set and the possible portfolio weights which can be expected to reduce the expected risk-adjusted returns of the fund. The concepts of liquidity and transferability drive asset selection and portfolio construction for UCIT funds. Broadly speaking transferable and liquid assets such as exchange traded assets are considered eligible but there are some exceptions. The use of derivatives is subject to stringent requirements that aim at protecting the investor from excess leverage and counterparty risk. ${ }^{18}$ Derivatives under the UCITS regime may only be entered into where the underlying of the derivative would otherwise be an eligible asset under the so called "look through rule". For reasons of space we report details about asset eligibility in Appendix. ${ }^{19}$ A second UCITS rule that can be expected to reduce the investment opportunity set relative to hedge funds is that physical (or uncovered) short selling of securities is prohibited for UCITS. ${ }^{20}$ Since there is evidence (Jones, Reed and Waller (2015)) that large short selling positions can be very profitable, restrictions on the

\footnotetext{
${ }^{18}$ The UCITS I directive already allowed hedging via derivatives in 1985, but in 2002 the UCITS III directive extended the permissible use of derivatives to speculation. Depending on whether derivatives are used to speculate or to hedge, funds that use them may have higher or lower risk than those that do not.

${ }^{19}$ The following categories of assets, for example, are not considered eligible: precious metals, real estate, commodities, funds of funds and non-UCITS hedge funds.

${ }^{20}$ However, it is possible to obtain synthetic short exposure by using derivatives, most commonly via swaps with an ISDA counterparty (on single names or the entire short book), or by using contracts for differences. However, these are imperfect solutions since they may not allow to replicate the payoff of a short position for each asset and they may do so at an additional costs for the intermediary involved.
} 
implementation of short strategies might reduce expected returns for ARUs compared to other hedge funds. A third UCITS rule that may affect the investment opportunity set is the diversification rule that is intended to protect investors from excessive exposure to the idiosyncratic risk posed by any single issuer. The foundation of diversification rules within the framework of UCITS is the so-called 5/10/40 rule as laid out in the UCITS Directive. The rule states that a UCITS cannot invest more than $10 \%$ of its NAV in securities issued by a single corporate issuer (the rules in relation to sovereign issuers are described below). Furthermore, the sum of all exposures greater than 5\% should not exceed $40 \%$ of the fund's NAV. This rule may, however, prevent portfolio managers from implementing high conviction ideas that require concentrated positions (Cohen, Polk and Silli 2010) including certain hedge fund activist strategies (Brav, Jiang, Partnoy, and Thomas 2008), and thus reduce the investment opportunity set. To the extent that these constrains the investment opportunity set and the possible portfolio weights it can be expected to reduce the expected risk-adjusted performance of the fund. This motivates the Performance Hypothesis which states that due to the more restrictive investment opportunity set ARUs have lower risk-adjusted performance than hedge funds.

Fourth, UCITS funds are required to have a separate risk management function and are subject to leverage limits, and value-at-risk limits, requirements that do not explicitly apply to equivalent hedge funds. These requirements can be expected to reduce the exposure of ARUs to market risk. We therefore test our Risk Hypothesis, which states that (for a given investment objective) the (systematic) risk of ARUs is lower than that of other HFs. European Union countries have some leeway in implementing the VaR management requirements of the UCITS directive. ${ }^{21}$ The UCITS Directive restricts the use of leverage with the objective of protecting investors from excessive borrowing, and has provisions that address the maximum amount of leverage funds can incur and how to ensure that funds have adequate coverage. Restrictions on the use of derivatives can work in the other direction, however, since they can limit a fund's ability to hedge against market downturns, which leads us to test for whether or not the returns on ARUs are more cyclical than those on other hedge funds. We use exposure to common risk factors (e.g., market beta) to assess the cyclicality of hedge fund returns. From a theoretical viewpoint, investment and risk restrictions may prevent managers from risk shifting

\footnotetext{
${ }^{21}$ Investment managers measure global exposure/leverage either using the (i) commitment approach or the (ii) Value at Risk ('VaR') approach. The commitment approach is appropriate for a UCITS that does not use complex derivatives or trade derivatives extensively. This approach is based on the market value of the asset underlying the derivative and sums up the aggregate absolute value of the underlying exposures' notional values. The VaR approach can be further subdivided into (i) an absolute and (ii) a relative VaR approach. The maximum absolute VaR limit is set at $20 \%$ over a 20 -day holding period and based on a $99 \%$ confidence interval.
} 
- that is, strategically changing portfolio volatility in order to maximize the value of implicit management incentive contracts and fees (Buraschi, Kosowski, and Sritrakul 2014). Of course, even without regulatory oversight it is possible for a hedge fund to have tight internal controls on risk taking. Indeed, Cassar and Gerakos (2013) use a sample of due diligence reports to find that funds using formal risk and stress testing models performed better during the extreme down months of 2008 and generally had less exposure to systematic risk. Their results also suggest that funds employing tests for $\mathrm{VaR}$ and for stress predicted their own performance more accurately in a short-term equity bear market. In addition, Aragon and Martin (2012) find that hedge funds using options deliver better performance and with less risk than those that do not use options. ${ }^{22}$ It is therefore important to investigate whether UCITS regulation can actually protect investors from financial risk.

Fifth, according to regulatory rules, UCITS funds must carefully monitor and manage liquidity risk and valuation; they must also account for liquidity risk when investing in any financial assets. This leads us to formulate our Liquidity Restrictions Hypothesis which posits that ARUs deliver lower average performance than funds with strict share restrictions, which are able to earn a liquidity premium for holding less liquid assets (Amihud and Mendelson 1986; Pastor and Stambaugh 2003).

The UCITS directive defines liquidity risk as "the risk that a position in the UCITS portfolio cannot be sold, liquidated or closed at limited cost in an adequately short time frame and that the ability of the UCITS to [repurchase or redeem its units at the request of any unit holder] is thereby compromised." These rules imply that funds should consider, for example, bid-ask spreads and the secondary market's quality. In practice, funds are effectively required to allow as much of $20 \%$ of their NAV to be redeemed at any time. Only $10 \%$ of NAV can be invested in illiquid assets - though all redemption requests must be honored even in this case. Funds that wish to remain UCITS-compliant must, at least twice each month, not only value their investments but also provide liquidity to their investors. In contrast, non-UCITS hedge funds are less regulated and so can accept longer redemption periods; they can even introduce "gates" and "side pockets" for illiquid, hard-to-value assets (Aiken, Clifford and Ellis 2014).

Furthermore, the distributional properties of ARUs and HFs are likely affected by the liquidity of their underlying assets. The UCITS directives contain a range of rules concerning concentration and counterparty risk. For example, exposure to any money market instrument or other security issued by a given party cannot exceed $10 \%$ of NAV; in combination with derivatives, it cannot exceed $20 \%$ of

${ }^{22}$ Our research is also related to that of Koski and Pontiff (1999) and of Almazan, Brown, Carlson, and Chapman (2004), who investigate the difference in performance between mutual funds that use derivatives and those that do not. 
NAV. Such restrictions reduce a UCITS fund's capacity to hold concentrated portfolios of potentially illiquid securities.

According to asset pricing theory, the return on an illiquid asset is associated with an illiquidity premium. ${ }^{23}$ Aragon (2007) finds that hedge funds with strict share restrictions (in the form of longer lockup, notice, and redemption periods) can earn a premium. Aragon, Liang, and Park (2013) report that onshore US funds are associated with greater share restrictions than offshore funds; these authors also provide some evidence that better performance is delivered by onshore than by offshore funds. Sadka (2010) demonstrates that liquidity risk explains the cross section of hedge fund performance. Teo (2011) shows that some HFs granting favourable redemption options are exposed to liquidity risk arising from asset-liability mismatch and since ARUs are relatively liquid it is interesting to examine whether they are more exposed to liquidity risk.

The difference in funding liquidity risk may also explain performance differences observed between ARUs and HFs. Frazzini and Pedersen (2014) present a model with leverage and margin constraints that vary by investor type. In their dynamic model with constrained investors, some investors cannot use leverage and therefore overweight high-beta assets; hence those assets yield lower returns. Other investors can use leverage, but they face margin constraints and thus may sometimes be forced to de-leverage; these investors underweight (or short-sell) high-beta assets and buy low-beta assets that they then leverage up. Hedge funds with longer notice and redemption periods than ARUs may be more exposed to this betting-against-beta factor. The reasoning just given indicates that our Liquidity Restriction Hypothesis is related to the effect of liquidity or share restrictions and tests whether less liquid funds (as defined by their notice and redemption periods) exhibit better performance, are more exposed to market liquidity risk (Pastor and Stambaugh 2003), or are more exposed to leverage and margin constraints (Frazzini and Pedersen 2014).

As mentioned previously, a major difference between ARUs and HFs concerns fund liquidity. Apart from their effects on fund performance, differences in fund liquidity raise the question of whether investors can exploit superior liquidity by periodically rebalancing their portfolio of funds. In particular, we look for evidence of differences between ARUs and HFs as regards performance persistence. On the one hand, an ARU's bi-weekly liquidity requirement may enable investors to exploit any performance persistence. On the other hand, the mandatory disclosure of a fund's investment strategies may be detrimental to its performance.

${ }^{23}$ Amihud, Mendelson, and Pedersen (2006) provide a comprehensive survey that discusses the role of liquidity in asset pricing theory. 
Glode and Green (2011) rationalize performance persistence for hedge funds by showing that it can be explained by the desire for secrecy. They argue that superior returns may not be entirely due to manager ability; in particular, outperforming the market may be attributable also to strategies or techniques that could be expropriated and exploited by others if they were adequately informed. This view is supported by the research of Agarwal, Jiang, Tang, and Wang (2013), who investigate the confidential holdings of hedge funds that are disclosed (with a delay) through filed amendments to SEC Form 13F. These authors document that the confidential holdings exhibit superior performance for up to 12 months yet usually take longer to build.

The UCITS rules require that funds publish a prospectus, annual and semi-annual reports, and a Key Investor Information Document (KIID). ${ }^{24}$ In other words, a UCITS fund must provide comprehensive details of its investment goals and strategies and of the associated risks. The implication is that alternative UCITS funds must disclose much more information about their trading strategies than do other hedge funds. In contrast, non-UCITS hedge funds are often sold through private placement and offered only to accredited or qualified investors in the United States and to sophisticated qualifying investors in Europe. When funds are not offered to the public there are fewer disclosure requirements, which may benefit these other hedge funds.

Thus our Persistence Hypothesis states that ARUs should exhibit less performance persistence than other HFs because the latter's trading strategies are more secretive. The performance persistence of these HFs may be driven also by their more stringent share restrictions generating a liquidity premium and hence a consistent alpha. Finally, in testing this hypothesis - and also as a robustness test - we check for whether performance persistence changes (for either ARUs or other HFs) after liquidity is taken into account.

\section{Description of Hedge Fund Universe}

\subsection{Absolute Return UCITS and Hedge Fund Databases}

In this section we describe the aggregate ARU and HF databases. We combine five major hedge fund databases - BarclayHedge, EurekaHedge, Hedge Fund Research (HFR), Morningstar, and TASS Lipper - to form an aggregate data set. Our sample period starts from January 2003, which is the first possible date to launch UCITS compliant absolute return funds, and ends to June 2013. Restricting the sample to funds that have reported at least 12 monthly returns, the sample contains 786 ARUs (104

\footnotetext{
${ }^{24}$ The KIID replaces the "simplified prospectus".
} 
defunct funds) with total assets under management (AUM) of around \$230 billion, and 23,204 HFs (12,112 defunct funds) with total AUM of around \$1,981 billion. Our sample is comprehensive in terms of both ARU and HF coverage. A leading absolute return UCITS index provider (ALIX) reports that it follows 794 funds as of February 2013. In a report dated that same month, Preqin claims there are 701 ARUs in existence.

It is not a trivial task to merge several commercial hedge fund databases and then identify unique hedge funds based on information about multiple share classes. The main reason is that commercial data vendors provide an identifier only for unique share classes and not for distinct hedge funds. We are able to identify unique hedge funds by way of the merging approach developed in Joenväärä, Kosowski, and Tolonen (2014). We match manually UCITS-compliant funds across different databases, because of a significant number of currency share classes, it is difficult to identify distinct UCITS-compliant funds. Appendix B.1. gives the details of our data gathering process. Because ARUs originate in the European Union, our focus is not limited to USD share classes but also incorporates funds that include (or deal exclusively with) non-USD share classes. ${ }^{25}$ For such funds we convert returns and AuM information into US dollars, using rates obtained from Bloomberg, before incorporating them into the analysis. Our consolidated database contains monthly net-of-fees returns, AuM, and several additional characteristics; these include manager compensation (management fee, performance-based fee, and existence of a high-water mark provision), share restrictions (length of lockup, notice, and redemption periods), domicile, currency, category of investment "style", and date of fund inception.

We focus on comparing absolute return UCITS funds (ARUs) and other hedge funds (HFs). According to Panel A in Figure 1, which graphs domiciles of the ARUs in our sample, the majority of ARUs are located in Luxembourg and Ireland. ${ }^{26}$ We compare ARUs to other hedge funds, including offshore hedge funds, US onshore hedge funds, and other European onshore hedge funds. Panel B of Figure 1 breaks down the entire sample of funds (i.e., ARUs plus HFs). ${ }^{27}$ In addition to the distinction between ARUs (group 1) and HFs (group 2) that we focus on in most of this paper, one could subdivide the group of HFs further into European onshore funds (group 2a), offshore hedge funds such

\footnotetext{
${ }^{25}$ Our data contains UCITS-compliant funds reported in several currencies (AUD, CHF, EUR, GBP, JPY, NOK, SEK and USD) Appendix B.1. provides more details about UCITS share classes.

${ }^{26}$ Instead of using UCITS structures, a hedge fund manager who targets European investors could also use Irish Qualifying Investor Funds (QIFs) and Luxembourg Specialised Investment Funds (SIFs).

${ }^{27}$ Broadly speaking, these fund types are more flexible than UCITS funds but less flexible than an offshore fund (e.g., a Cayman fund).
} 
as Cayman funds (group 2b), and onshore US-domiciled hedge funds such as Delaware funds (group 2c). Investor types differ significantly among these various fund structures. Hedge fund managers use offshore vehicles for non-US investors and for non-US-taxable investors but use US onshore funds for US-taxable investors. Both ARUs and other UCITS vehicles mainly target retail investors. Hedge fund management companies that aim to sell their funds to EU investors can also obtain an authorization under the AIFMD, which grants the right to manage alternative investment funds in other EU member states and/or to market units in alternative investment funds to professional investors.

\section{[[ Insert Figure 1 about here ]]}

We classify funds into 11 main categories by investment strategy: CTA (Commodity Trading Advisor), Emerging Markets, Event Driven, Global Macro, Long Only, Long/Short Equity, Market Neutral, Multi-Strategy, Relative Value, Sector, and Short Bias. Figure 2 depicts the distribution of these strategies (and their AuM) across geographic regions. We observe some differences in the distribution of ARUs and other hedge funds across investment strategies. Therefore, we control for strategy effects carefully while conducting our empirical results.

\section{[[ Insert Figure 2 about here ]]}

Table 1 presents the aggregate AuM, number of funds, and attrition rates for both the HF and the ARU universe at the end of each calendar year. The reported values show that growth has been extremely rapid for the ARU universe over our sample period, ${ }^{28}$ during which aggregate AuM as well as the number of funds increased significantly.

\section{[[ Insert Table 1 about here ]]}

Table 1 shows that, on average, the attrition rate of HFs is significantly higher than that of ARUs; by the end of the sample period, however, the two rates were nearly the same. From 2003 to 2009, the ARU attrition rate was negligible, so its increase coincided with the 2010-2013 period.

\footnotetext{
${ }^{28}$ We calculate aggregate hedge fund AuM figures using December observations because the values reported for that month are (in the case of hedge funds) widely considered to be the most accurate.
} 
Conversations with industry contacts have led us to believe that there are two main reasons why the ARU attrition rate is normally low. First, from 2003 onward there were many management companies that began to offer alternative ARU funds; hence there are relatively few closed (or defunct) ARU funds in the database. Second, and more importantly, it was not until 2009 that the BarclayHedge, EurekaHedge, HFR, and Morningstar databases started gathering information on whether or not a given fund is UCITS-compliant. Therefore, if a fund moved to the "graveyard" module of a database before that year, it did so sans any variable indicating whether or not the fund was UCITS-compliant. Later in the sample period, commercial databases did provide UCITS indicator information for active funds but not for those funds already in the graveyard. In other words, commercial databases provide comprehensive data only for the ARUs that survived. ${ }^{29}$ As a consequence, the average ARU return could be biased upward at the beginning of our sample (Fung and Hsieh 2000, 2009; Liang 2000). Our results can therefore be viewed as a conservative estimate of the underperformance of ARUs on average, which underscores the importance of examining subsamples of the data in light of the potential survivorship bias in the data for ARUs. We take that approach and also mitigate backfill bias by excluding the first 12 return observations and also excluding tiny funds (i.e., those with less than $\$ 5$ million in AuM).

\subsection{Differences in Fund-Type Characteristics}

We next examine how fund characteristics differ between ARUs and HFs as well as across hedge fund domiciles. On average, we find that HFs are smaller, charge higher fees, and impose tighter share restrictions. Among hedge funds, redemption restrictions are tightest for US-domiciled funds and loosest for European funds.

Table 2 reports fund size and age - as well as compensation structure and share restriction variables - for both HFs and ARUs. It shows that an average ARU (with a mean size of \$246.02 million) is larger than its average HF peer (\$162.98 million). This finding seems counterintuitive until one considers that UCITS regulation imposes minimum capital requirements whereas the relatively smaller size of most HFs makes them generally much less subject to regulation. Moreover, compliance and other fixed costs associated with running a UCITS fund are probably higher than for a non-UCITS hedge fund, as indicated by the many small HFs whose economic viability could be jeopardized by compliance. Among HFs, US-domiciled funds are smaller than their offshore and European peers. We

\footnotetext{
${ }^{29}$ Because UCITS hedge funds are a relatively recent development, it is possible that some funds we now classify as UCITS would have been classified as non-UCITS in the early part of the sample.
} 
define a fund's age based on the inception date it reports to data vendors. We find that, on average, HFs are slightly older (6.31 years) than ARUs (4.82 years).

\section{[[ Insert Table 2 about here ]]}

Given that the UCITS format is dominated by mutual funds, we expect that the fees ARUs charge will be close to the fees charged by mutual funds and thus lower than those charged by hedge funds. We find that the average HF management fee is $1.54 \%$, or somewhat higher than the average ARU fee of $1.29 \%$. Hedge funds also charge higher performance-based fees and impose high-water mark provisions more often. Indeed, the average HF performance-based fee is $17.66 \%$ as compared with $12.38 \%$ for the average ARU. Hedge funds domiciled in Europe charge lower incentive fees than do offshore and US-based funds. Therefore, performance differences between HFs and ARUs could be explained in part by the latter's charging of lower performance-based fees. Theoretical models and empirical evidence both suggest that such compensation-structure variables are associated with managerial incentives and a greater likelihood of higher gross returns. At the same time, however, higher fees should - by construction - also imply lower net (after-fee) returns for investors.

Regulations stipulate that ARUs provide at least bi-weekly liquidity to investors, so it is not surprising to find that HFs impose significantly tighter share restrictions than do ARUs. One fourth of HFs impose a lockup period and allow investors only monthly or quarterly redemptions (and with 30 day advance notice). In sharp contrast, more than half of ARUs provide daily redemptions and impose no lockups.

Among HFs, lockup periods are most frequently imposed by US-based funds, which have the strictest redemption terms in general. European onshore HFs impose relatively lighter redemption terms than other hedge funds. For instance, whereas Irish QIFs are required to offer at least quarterly redemptions, their offshore and US counterparts need not follow such a rule. We are thus motivated to investigate how the looser share restrictions of European hedge funds affect their performance.

\section{Misvaluation and Operational Risk}

This section is devoted to examining valuation and operational risk differences between ARUs and HFs. 


\subsection{Suspicious Patterns in Reported Returns}

We start by comparing differences between ARUs and HFs in terms of suspicious returns. Based on the argument of tighter oversight, our Misvaluation Hypothesis posits that ARUs are less likely than HFs to manipulate their reported returns. We investigate this issue using a set of so-called red flags, proposed by Bollen and Pool (2012), that are designed to detect suspicious patterns in reported fund returns. ${ }^{30}$ Those patterns include: (i) a discontinuity in the distribution of hedge fund returns; (ii) two measures of low correlation between hedge fund returns and the returns on style factors; and (iii) a family of data-quality indicators, such as the percentage of negative returns and the number of exactly zero returns. Yet as mentioned previously, it is not straightforward to distinguish between asset illiquidity and returns misreporting. With regard to this distinction, Casser and Gerakos (2010) claim that asset illiquidity is the main factor driving anomalous properties of self-reported hedge fund returns. So that we can improve our ability to distinguish among different interpretations of suspicious patterns in returns, we investigate this issue using a large set of proxies for such misreporting.

Table 3 reports the results. We start by comparing the asset illiquidity of ARUs and HFs. Panel A of the table shows the first-order coefficient in a MA(1)-model of fund returns. HFs have significantly more autocorrelation than ARUs (0.96 versus $0.26, t=15.17)$. This finding is consistent with ARUs being required to provide at least bi-weekly redemptions to investors; because HFs can impose longer redemption, notice, and lockup periods, they are better positioned to harvest the premiums for investing in less liquid assets. Even so, autocorrelation could still be due to misreporting. We explore the impact of liquidity on performance in a separate hypothesis below.

\section{[[ Insert Table 3 about here ]]}

We next explore the frequency of red flags in fund reported returns. We find that HFs exhibit suspicious patterns in reported returns significantly more often than do ARUs. In addition, two measures of low correlation between hedge fund returns and the returns on style factors - as well as three of our four data-quality indicators - suggest that the patterns of self-reported HF returns are comparatively more suspicious.

Panel B of the table concerns the red flag of a kink. This abnormal rate of reporting small losses

\footnotetext{
${ }^{30}$ Following Bollen and Pool (2012), we require each fund to have at least 24 return observations over the period from January 2003 to June 2013. See Appendix B.2.1. for more details about these red flags. We find very similar results using pre-2009 data that do not have any problems in defining whether a fund is UCITS-compliant or not.
} 
is significantly higher for hedge funds, which indicates that there is more discontinuity in the returns distribution of HFs than of ARUs (0.16 versus $0.11, t=-6.70)$. However, given Jorion and Schwarz's (2014) demonstration that incentive fees can "mechanistically" create a kink in the net return distribution, discontinuities in observed hedge fund return do not conclusively establish that manipulation has occurred.

Nonetheless, our other proxies support the view that HFs manipulate returns more. Panel C of Table 3 shows that, as measured by low correlation between either hedge fund returns or the returns of style factors, the reported returns of HFs are more suspicious than those of ARUs. Hedge funds have significantly larger mean Index $R^{2}$ than ARUs $(0.09$ vs $0.02, t=17.47)$, that is, their returns are less explained by their corresponding style index. ${ }^{31}$ Hedge funds have significantly smaller mean $\operatorname{Max} R^{2}$ than ARUs (0.43 vs $0.57, t=-22.15)$, that is, their returns are less explained by exposure to common risk factors. ${ }^{32}$

Furthermore, Panel D of table reports four measures of data-quality showing that hedge funds exhibit more suspicious patterns in reported returns that UCITS funds. We find that hedge funds have significantly more repeats $(0.03$ vs $0.02, t=6.18)$, more zero returns $(0.38$ vs $0.27, t=3.59)$, less negative returns $(0.38$ vs $0.42, t=-11.77)$, and more uniformity of the last digit in reported returns (16.81 vs $15.79, t=4.25$ ) then UCITS-compliant funds.

In Panel E we combine our measures in reporting the sum total of red flags as well as each measure's first principal component. Both of these metrics indicate that returns patterns are less suspicious for UCITS-compliant than for noncompliant funds.

Finally, we investigate whether the hedge funds' domiciles are driving the results. For example, less regulated offshore HFs might exhibit more return manipulation than other funds. However, because we find quantitatively similar results across fund domiciles, it seems reasonable to conclude that HFs are more prone than ARUs to return manipulation and that UCITS regulation does protect investors. $^{33}$

\footnotetext{
${ }^{31}$ Index $\mathrm{R}^{2}$ is the $p$-value of the slope coefficient from a regression of fund returns on a corresponding equally-weighted style index, with higher values denoting more return manipulation.

${ }^{32} \mathrm{Max} \mathrm{R}^{2}$ is the maximum adjusted R-square of fund returns against the seven factors of Fung and Hsieh (2004) and the four option factors of Agarwal and Naik (2004), with lower values denoting more return manipulation; the optimal factors maximizing the adjusted R-square are found via stepwise regression, with a maximum number of factors of six

${ }_{33}$ Appendix B.1.2. provides the statistical tests for the funds that are domiciled in Europe.
} 


\subsection{Operational Risk}

As mentioned on several occasions, the primary goals of UCITS regulation include protecting retail investors and reducing the risk of funds. Therefore, we next examine whether the regulation succeeds in this endevour and whether measures of operational risk are, as anticipated, lower for ARUs than for HFs. Contrary to the prediction of our Operational Risk Hypothesis, we find evidence that ARUs are not less exposed to operational risk - and also tend to have more potential conflicts of interest than HFs.

\subsubsection{Past Violations and Conflict of Interest}

Similar to Brown, Goetzmann, Liang, and Schwarz (2008, 2009), we construct two measures of operational risk - problem indicator and Omega score. ${ }^{34}$ We start by classifying as "problem" funds those that answered Yes to at least one question in Item 11 of their Form ADV filing. Item 11 requires filers to identify any problems exhibited by fund management or its advisory affiliates: felonies; investment-related misdemeanors; any agency, SEC, Commodity Futures Trading Commission (CFTC), or self-regulatory issues; and pending disciplinary actions or civil lawsuits. The problem indicator is only available for those funds that file Form ADV. To address this issue, we estimate Omega score for each fund by defining it as the fitted value from a Probit model of the problem indicator against a number of fund characteristics. ${ }^{35}$ In other words, Omega score predicts the problem indicator, but is applicable to all funds, not just those registered with SEC.

Surprisingly, Panel A of Table 4 shows that a larger proportion of ARUs are problem funds than is the case for HFs. In addition, we find that Omega-scores tend to be significantly higher for ARUs than for HFs. This finding suggests that ARUs are more exposed than HFs to operational risk. One caveat is that not all EU-based funds file a Form ADV with the US-based regulator (i.e., the SEC). However, there is no statistical difference between ARUs and HFs in ADV-filing (0.24 vs 0.26, $t=$ -1.47). Observe that we are comparing EU-domiciled funds (including ARUs and other non-UCITS onshore hedge funds domiciled in Europe) with offshore and US hedge funds; as a result, the conclusions are more nuanced. We find both a larger portion of problem funds and a higher level of

\footnotetext{
${ }^{34}$ Appendix B.2. gives the details how operational risk measures are constructed.

35 The other possible Omega's definition would be the canonical correlation of fund characteristics against Form ADV variables, which leads very similar conclusions. Similar to Brown, Goetzmann, Liang, and Schwarz (2008, 2009, 2012), we use as fund characteristic; fund age, fund size, management fee, incentive fee, high-water mark, notice period, lockup dummy, leverage dummy, as well as average return and standard deviation of fund return based on a 12-month rolling window.
} 
operational risk for EU-domiciled funds than for other funds.

\section{[[ Insert Table 4 about here ]]}

Toward the end of better understanding the sources of operational risk, we present a set of proxies for potential external and the internal conflicts of interest. We adopt a univariate setting and focus initially on external relationships between the fund and other entities that represent potential conflicts of interest. The first four data columns in Panel B of Table 4 report the frequencies of responses to questions such as whether the manager has a related broker/dealer, commodities broker, investment adviser, bank or insurance company and whether the manager is the sponsor of a limited liability partnership (LLP). Again, we find clear evidence that ARUs have answered Yes to these questions more often than HFs have. Out of 6 questions, a typical ARU (resp., HF) gave 2.54 (resp., 1.85) Yes answers. This finding is confirmed by construction the first principal component of external conflicts of interest. Just as we concluded from the evidence in Panel A, in this case also we find that geographical location matters. In other words, there are more determining factors than simply whether or not the focal fund is UCITS-compliant. The last three columns of Panel B show that European hedge funds have more potential external conflicts than do offshore and US-based funds. The most interesting difference is that both ARUs and European HFs are more likely than other funds to have connections with particular banks and brokers.

Panel $\mathrm{C}$ of Table 4 reports differences among fund types in terms of various proxies for possible internal conflicts of interest. Consistent with the findings already reported, ARUs (on average) answered Yes to questions addressing internal conflicts of interest more frequently than did HFs; the implication is that ARUs exhibit more internal conflicts. Although these results are less clear-cut than those for external conflicts of interest, the total frequency of internal conflicts (see Panel D) is still higher for ARUs than for HFs - a result that is statistically significant at the 5\% level. This finding is apparently driven by the RecSalesInterest and OtherResearch variables, which suggests that ARUs have more conflicts with related parties that have a sales interest in recommending securities. In addition, external research is more often employed by ARUs than by HFs. ${ }^{36}$

\section{[[ Insert Table 5 about here ]]}

\footnotetext{
${ }^{36}$ In unreported results we find no statistically significant differences in conflicts of interest between ARUs (first data column in all Table 4 panels) and a subset of European onshore funds - namely, QIFs and SIFs (fifth data column).
} 


\subsubsection{Probit Model Analysis on the Past Violations}

Finally, we examine whether the UCITS structure is related to past violations in a multivariate setting. After controlling for various conflicts of interest, we estimate a multivariate Probit model in which the dependent variable indicates whether or not the focal fund has had a past violations (i.e., "problems").

We address potential sample selection bias using the Heckman (1979) method. It may be the case that not all EU-based funds file a Form ADV with the US-based regulator (i.e., the SEC). An important identification assumption in Heckman's correction is that there are some variables that explain the fund's selection to file Form ADV, but these variables do not explain the fund's past violations. As an exclusion restriction, we employ a set of fund characteristics (fund age, fund size, management fee, incentive fee, high-water mark, notice period, lockup dummy, leverage dummy, as well as average return and standard deviation of fund return based on a 12-month rolling window). As we see from Table 2, fund characteristics for funds domiciled in US and Europe tend to be significantly different between domiciles. In addition, the Probit model analysis on the problem variable conducted by Brown, Goetzmann, Liang, and Schwarz (2008) show that fund size, high-water mark and average returns do not explain past violations (See, their Table III). Hence, as an appropriate first stage selection model, we regress (Probit) an ADV indicator (equal to whether the fund's advisor has a Form ADV report as of June 2013) against fund characteristics discussed above. To save space, we report the results in Appendix B.2.2. The inverse Mills ratio of the fitted probability from this Probit regression constitutes the fund's $\lambda$ measure, which is a proxy for the fund's propensity for filing Form ADV.

Table 5 reports the results for the second stage Heckman equation, where the inverse Mills's ratio (i.e., Heckman's lambda) is used for addressing sample selection bias. As a baseline, the first two data columns report Probit model results in which the independent variables exclude the indicators for conflict of interest and only add a variable that captures the first principal component of Bollen and Pool's (2012) red flags. At first it appears that ARUs are more likely than HRs to have had (or be having) problems. Yet when we add control variables for conflicts of interest, we find that the ARU variable becomes insignificant. As it turns out, the higher probability of being a problem fund is instead strongly (indeed, significantly) associated with having a related broker-dealer - and also with other conflict-of-interest indicators. Hence, we can conclude that the fund's UCITS structure itself is not a primary reason for past violations. However, both our univariate and multivariate analyses suggest that UCITS-compliant funds do not have lower operational risk measures compared to their less regulated 
hedge fund counterparts.

\section{Performance Hypothesis and Risk Hypothesis}

To address our Performance and Fund Risk Hypotheses, we use portfolio sorts and fund-level measures as well as multivariate regressions with Heckman correction to show that our results are robust.

\subsection{Portfolio Sorts}

In Section 2 we noted that the UCITS directive imposes a range of restrictions on eligible assets and permitted strategies which can be expected to adversely affect the investment opportunity set and riskadjusted performance of ARUs compared to other hedge funds. In order to evaluate the overall performance of funds, we construct equal-weighted (EW) and value-weighted (VW) portfolios over the sample period from January 2005 to June 2013. We exclude the first two years from the analysis because there are only very few UCITS-compliant funds and issues related to survivorship bias as discussed earlier.

To evaluate fund performance, we augment the Fung and Hsieh (2004) model with emerging market and currency factors because of the potentially global geographical exposure of ARUs (See Panel B of Figure 2). As factors, we use the excess return on the S\&P 500 index (SP), the return on the Russell 2000 index minus the return on the S\&P 500 index (SIZE), the excess return on 10-year Treasuries (CGS10), the return on Moody's BAA corporate bonds minus that on 10-year Treasuries (CREDSPR), the excess returns on look-back straddles using bonds (PTFSBD), currencies (PTFSFX), and commodities (PTFSCOM), and the MSCI Emerging Market index (MSEMKF); the currency risk factor is constructed following Lustig, Roussanov, and Verdelhan (2011). ${ }^{37}$ Use of the currency risk factor is motivated by Banegas, Gillen, Timmermann, and Wermers (2013), who document its importance when evaluating how well European mutual funds perform.

Panel A of Table 6 presents both risk-adjusted performance measures and systematic risk loadings for EW portfolios consisting solely of ARUs or HFs. ${ }^{38}$ We find that, during the 2005-2013 sample period, ARUs had negative risk-adjusted performance (alpha of $-1.061 \%$ per year) whereas

\footnotetext{
${ }^{37}$ We obtain data for the three equity market-related factors (SP, SIZE, and MSEMKF) from Datastream and for the two bond factors (CGS10 and CREDSPR) from the Federal Reserve Board's H.15 reports. Data for the three primitive trendfollowing factors (PTFSBD, PTFSFX, and PTFSCOM) are downloaded from David Hsieh's Web page and the currency risk factor is downloaded from Adrien Verdelhan's Web page.

${ }^{38}$ Throughout the whole paper, we mitigate backfill bias by excluding the first 12 return observations and also very small funds (AuM $<\$ 5$ million). Unreported results are quantitatively similar when we use the Getmansky, Makarov, and Lo (2004) technique to unsmooth fund returns.
} 
HFs had positive risk-adjusted performance (alpha of $+1.176 \%$ per year). It is worth noting that the difference in risk-adjusted performance between these two groups is statistically significant at the $1 \%$ level. This result is robust to using VW portfolios, as shown in Panel B of the table. Hence, differences in fund size distributions (see Panel $\mathrm{C}$ of Figure 2) between ARUs and HFs are unlikely to drive performance results.

We next test the Risk Hypothesis formulated in Section 2 which states that ARUs have lower market risk loadings due to UCITS' value-at-risk and leverage restrictions as well as other risk management requirements. We find that the exposure to the stock market risk is significantly higher for UCITS-compliant funds than hedge funds. ${ }^{39}$ Thus, using portfolio sorts we find support for the Fund Performance but not for the Risk Hypothesis.

\section{[[ Insert Table 6 about here ]]}

\section{2 Fund-level Measures}

Now we test both the Performance and Risk Hypothesis using fund-level measures. In doing so we estimate all fund-level measures for each individual fund that has at least 24 return observations using the Getmansky, Lo and Makarov (2004) technique for unsmoothed returns, which corrects for artificially smooth returns that could be the result of misreporting or illiquidity. We take the crosssectional median for each measure and test the difference between HFs and ARUs. ${ }^{40}$ To address potential survivorship bias in ARU returns, in Panels C and D of Table 6 we examine two subsamples: from January 2005 to December 2009 and from January 2010 to June 2013. It could be that issue related to survivorship bias rendered the median difference for average returns and Sharpe ratios statistically insignificant during the earlier period; during the later period, however, these medians are significantly higher for HFs.

Panels C and D show that HFs exhibit better risk-adjusted performance and lower risk than do ARUs - especially during the later period, when there are no problems stemming from attrition rates. ${ }^{41}$

\footnotetext{
${ }^{39}$ We find similar results once we run tests after correcting for autocorrelation using Getmansky, Makarov and Lo (2004) approach.

${ }^{40}$ The conclusions are not changed if we instead use mean tests. As a baseline, we report medians because they are more robust with regard to outliers.

${ }^{41}$ In Appendix, we find that are conclusions are not sensitive to the benchmark model. To confirm this issue, following Titman and Tiu (2011) we use 26 risk factors in a stepwise regression model to estimate alphas and risk loadings more precisely. The factors used are the augmented Fung and Hsieh (2004) factors, four US Carhart factors, four Global Carhart factors, four European Carhart factors, two Agarwal-Naik option factors (Call_OTM and Put_OTM), the Pastor and Stambaugh (2003) liquidity risk factor, the Frazzini and Pedersen (2014) betting-against-beta factor, and the Asness, Frazzini, and Pedersen (2013) "quality minus junk" factor.
} 
The qualitative conclusions are not sensitive to whether we use standard measures or other, more sophisticated metrics that account not only for potential performance manipulation and nonlinearities in fund returns but also for omitted risk factors in those returns. Restrictions on the use of derivatives, together with other impediments to implementing hedge fund-like strategies, may help explain the worse performance and higher risk of ARUs.

Neither performance measure manipulation nor nonlinearities in hedge fund returns can explain why HFs are less risky than ARUs. According to Goetzmann, Ingersoll, Spiegel, and Welch (2007), standard performance measures (e.g., alpha and the Sharpe ratio) can be "gamed" by means of timevarying leverage and certain option strategies that are more often used by HFs. We therefore compare manipulation-proof performance measures (MPPMs) between HFs and ARUs. These measures are significantly higher for HFs, which suggests that HFs do not outperform ARUs by engaging in “information-less" option strategies.

Also, using fund-level measures, we do not find support for the Risk Hypothesis. Contrary to the hypothesis, we find that median volatility and expected shortfall are actually greater for ARUs. ${ }^{42}$ To understand the sources of these differences in risk further, we estimate measures of both systematic and idiosyncratic risk for HFs and ARUs. We find that the median of the composite systematic risk measure of Bali, Brown and Caylayan (2012) is greater for ARUs than HFs. We also measure systematic risk in terms of $R^{2}$ with respect to the 9-factor model (Titman and Tiu 2011). Our findings suggest that $R^{2}$-values are significantly higher for ARUs than for HFs, which means that ARU returns are less countercyclical than HF returns. This result is consistent with the hurdles encountered when transporting hedge fund techniques to the UCITS universe. Because UCITS funds face restrictions regarding the use of derivatives and short-selling, their consequent reduced flexibility may well make ARU returns less countercyclical than those of HFs. Our results therefore suggest that, even though UCITS regulation puts strong emphasis on protecting investors from market risk, hedge funds that are less regulated seem to have internal controls that discourage them from taking excessive risk.

In univariate tests, fund-level alphas cross-sectional averages are assumed to be independent. Next, we relax this assumption by means of multivariate regressions.

\footnotetext{
42 The results are quantitatively similar when we measure HF and ARU tail risk by instead using maximum drawdown as estimated via the geometric cumulative returns.
} 


\subsection{Multivariate Regression Analysis}

We conduct multivariate regressions to investigate whether differences in redemption terms, fund size, and age - or whether proxies for managerial incentives - explain the observed performance differences between HFs and ARUs.

We first estimate monthly augmented Fung and Hsieh (2004) alphas for each of the individual funds with at least 24 return observations. ${ }^{43}$ We then run multivariate regressions in which alphas are explained by the UCITS indicator variable and a set of fund characteristics that have been found (in the literature) to account for fund performance differences. The following panel regressions are estimated over the period from January 2005 to June 2013:

$$
\text { Alpha }_{i, t}=\gamma_{0}+\gamma_{1} A_{R U_{i, t}}+\gamma_{2} \text { Restrictions }_{i, t}+\gamma_{3} \text { Control Variables }_{i, t}+\varepsilon_{i, t} .
$$

Here $A l p h a_{i, t}$ denotes the augmented Fung and Hsieh (2004) alpha of a hedge fund $i$ at time $t ; A R U_{i, t}$ is a dummy variable set equal to 1 if fund $i$ is UCITS-compliant (and set to 0 otherwise); and Restrictions $_{i, t}$ are fund $i$ 's share restrictions in the form of minimum investment requirements and its lockup and restriction periods. The Control Variables $_{i, t}$ term incorporates fund $i$ 's management and incentive fees, high-water mark provision (if any), and time-variant characteristics that control for fund size, flow, and age; the importance of these latter factors has been demonstrated by Aggarwal and Jorion (2010) and by Teo (2010, 2011).

\section{[[ Insert Table 7 about here ]]}

Overall, the results presented in Table 7 confirm that ARUs have lower risk-adjusted returns than HFs even when control variables are included. The economic magnitude of risk-adjusted return difference between ARUs and HFs is significant, being $1.44 \%$ per annum. This suggests that regulation impacts indirectly on investment funds.

To address potential sample selection bias that may arise from the fact that the fund's legal structure choice may not be exogenous, we follow the recent hedge fund literature (Ramadorai 2012, 2013 and Teo 2011) and employ the Heckman (1979) two stage-procedure to correct for possible sample selection bias. An important identification assumption in Heckman's correction is that there are some variables that explain the fund's selection to be structured as UCITS-compliant, but these

\footnotetext{
${ }^{43}$ We use the Getmansky, Makarov, and Lo (2004) technique to unsmooth fund returns.
} 
variables do not explain the fund's risk-adjusted returns. If there is no such exclusion restriction, the regression model is identified only by distributional assumptions about the residuals, which could lead to problems in estimating the parameters of the model. As an exclusion restriction, we employ fund family size at inception. This variable is also used by Teo (2011). It is also particularly well-suited for us, because the fund's legal structure could be linked to variables known at inception. For larger fund families, it would be easier to absorb to compliance costs and minimum capital requirements. As Teo (2011) argues, at the same time, it is very unlikely that the family size at inception significantly impacts on fund performance several months after the inception. We also use management fee and incentive fee as additional variables in selection equation reported in Columns 4 and 5. We find that all of these three variables are highly significant. Larger fund families have higher propensity to set up UCITS-compliant funds as we expected. Both management fees and incentive fees are lower for UCITS-compliant funds compared to hedge funds. In Columns 6 and 7, we report results for the regression equation. We find that even after the selection bias correction that the coefficient for ARU indicator is positive and statistically significant. This suggests that the selection bias does not drive our findings.

We next focus on the role of control variables. Regulation of remuneration policies has been a focal point after the financial crisis. We find that managerial incentives are important drivers of crosssectional performance differences between funds. According to a recent Financial Times article:

US fund groups have rapidly expanded into Ucits funds in recent years as a way of accessing both the European and Asian markets. More than 1,000 such funds, with assets of $€ 765 \mathrm{bn}$, are now domiciled in Ireland alone ... . However, "the US managers that have set up Ucits funds are extremely exercised" about proposals from the European Parliament's economic and monetary affairs committee to limit asset managers' bonuses to 100 per cent of their salary. ${ }^{44}$

The above extract raises the question of what the effect of remuneration restrictions would be on ARUs and to our knowledge this question has not been previously studied in the literature. We use our data to address this question. The ARUs funds in our sample operate without regulatory restrictions on remuneration and are free to set their fee and compensation structures. We find that performance increases with incentive fees and so, if UCITS-compliant funds were forced by regulators to implement bonus caps, the likely effect would be to drive an additional wedge between the (average) performance

\footnotetext{
${ }^{44}$ Steve Johnson, "EU pay cap a concern for US funds," Financial Times, 24 March 2013.
} 
of ARUs and HFs. Of course, such regulatory behavior would also have welfare implications for pension funds that invest in alternative investment funds. We leave the analysis of such consequences to future work.

To sum up, we find strong support for the Fund Performance Hypothesis stating that hedge funds deliver higher risk-adjusted returns compared to UCITS-compliant funds. In contrast, we reject the Risk Hypothesis, because our results suggest that ARUs are riskier than HFs. We find that ARUs are more exposed to systemic risk even after adjusting for autocorrelation in fund returns.

\section{Liquidity Restriction Hypothesis}

In this section we examine our Liquidity Restriction Hypothesis by investigating the effects of redemption restrictions and leverage limits on fund performance; in doing so, we shed some light on the economic mechanism that enables funds with strict redemption restrictions to generate high performance nonetheless. Finally, we identify and compare the most closely matched pair of ARU and non-UCITS hedge funds within a given management company and under the same fund manager. This allows us to measure effect of liquidity restrictions when the fund skill is fixed.

\subsection{Liquidity-Performance trade-off}

The preceding performance comparison may not be fair, given that ARUs and HFs have very different liquidity terms and share restrictions. So that we will not be comparing apples and oranges, we examine the Liquidity Restriction Hypothesis.

The UCITS regulations stipulate that Absolute Return UCITS must offer at least bi-weekly redemptions to investors. We divide HFs into three groups based on the restriction period (defined as the sum of redemption and notice periods), and we then test whether "liquid" and "illiquid" HFs differ from ARUs in terms of performance. We use the Frazzini and Pedersen (2014) betting-against-beta (BaB) factor and the Pastor and Stambaugh (2003) liquidity risk (PS) factor to test effects related to leverage constraints and liquidity risk. ${ }^{45}$ To adjust for potential domicile effects, we compare ARUs against other non-UCITS funds that are domiciled in Europe; note that EU-domiciled hedge funds

\footnotetext{
${ }^{45}$ Betting-against-beta factor from Andrea Frazzini's Web page; liquidity risk factor from Lubos Pastor's Web page.
} 
typically impose longer redemption and notice periods. ${ }^{46}$

Panel A of Table 8 shows that the risk-adjusted average performance of ARUs converges with that of liquid HFs when we compare liquidity-matched portfolios. Both 9-factor and 11-factor alphas are statistically indistinguishable for ARUs and HFs that provide at least bi-weekly liquidity.

\section{[[ Insert Table 8 about here ]]}

Panel B of the table documents that European onshore funds exhibit significant risk-adjusted returns and liquidity trade-off. Funds with long redemption periods outperform those with short periods, a dynamic that is at least partly explained by the former's monotonic exposure to both the $\mathrm{BaB}$ and PS factors. This finding is partly driven by the importance of leverage constraints and liquidity risk, as is shown by our results for the 11-factor model. We find that exposure to the Frazzini and Pedersen (2014) betting-against-beta factor is highest (resp., lowest) for funds with the longest (resp., shortest) restriction periods. In results not reported here, we also find evidence that this relationship is monotonic in terms of the Patton and Timmermann (2010) monotonicity test. The 11-factor alpha, which includes the Frazzini and Pedersen (2014) and Pastor and Stambaugh (2003) factors, is lower than the 9-factor alpha - especially for funds with tight restrictions. We are thus led to investigate whether or not illiquid European onshore funds outperform ARUs.

Panel C in Table 8 reports rather different results for illiquid versus liquid HFs, since both 9and 11-factor alphas are significantly higher for illiquid HFs than for ARUs. Hedge funds that provide the strictest redemption terms deliver the best performance, whereas funds that guarantee investors the possibility of redeeming on at least a bi-weekly basis deliver the lowest performance. This implies that the indirect cost of UCITS rules is in terms of risk-adjusted performance difference from $2.57 \%$ to $3.05 \%$ per annum.

In sum, leverage constraints and liquidity risk mark important differences between illiquid and liquid funds but do not indicate differences in their loadings on market liquidity risk. We emphasize that only for illiquid HFs do we find a positive and statistically significant loading on the BaB factor, and we find no evidence that liquidity risk is greater for illiquid HFs than for ARUs. Thus the evidence suggests that leverage constraints may be less binding for hedge funds imposing long restriction periods.

\footnotetext{
46 The liquidity-performance trade-off results hold for other hedge funds domiciled offshore or in the United States; these results are not documented here (owing to space limitations) but are available from the authors upon request.
} 


\subsection{Comparing UCITS and Non-UCITS Pairs Managed by the Same Firm or Fund Manager}

Selection bias is an important concern when comparing ARUs and other HFs. We previous section used the Heckman (1979) correction to show that our results are robust to selection bias. An alternative approach to addressing selection bias - yet one that is also not sensitive to the specific model used in the first stage of the Heckman correction - is to compare funds only from management companies that feature comparable UCITS and non-UCITS funds. Recall from Section 1 that many hedge fund management companies now offer UCITS-compliant funds not only for "offshore" hedge funds but also for pure hedge funds. We therefore match, within a given management company, the closest possible UCITS and non-UCITS share class pairs. We gather from the EurekaHedge database 276 sideby-side management cases involving 138 UCITS-compliant funds and 164 hedge funds.

First, we run the regression within firms that manage both UCITS and non-UCITS funds. Our aim is to identify fund-specific characteristics that drive the performance difference between the focal firm's UCITS and non-UCITS funds, and the two leading candidates are liquidity and leverage. The capacity of HFs to impose tighter share restrictions may help them manage capital flows more efficiently and thereby facilitate their implementation of arbitrage strategies with longer-term horizons. Regulations limit the ability of UCITS-compliant funds to exploit leverage, whereas hedge funds can be relatively more leveraged. Frazzini and Pedersen (2014) point out that, although UCITS funds encounter more leverage constraints, hedge funds typically face margin calls during times of financial stress.

To address these issues, we run the following panel regression within management companies that manage both types of funds or manage simultaneously UCITS-compliant funds and hedge funds:

$$
R_{m, t}^{H F}-R_{m, t}^{U C I T S}=\gamma_{0}+\gamma_{1} \text { Restriction dummy }+\gamma_{2} \Delta \text { Leverage }+\gamma_{3} \Delta \text { Controls }+\varepsilon,
$$

where the left-hand side is to the return difference between the closest possible UCITS-compliant and noncompliant fund pair offered by the focal management company. ${ }^{47}$ In Panel A, we restrict the sample to pairs coming from the same management company, while Panel B reports the results for managers that simultaneously manage UCITS-compliant funds and hedge funds. The term Restriction dummy gets a value of 0 if both of the funds in a pair provide at least bi-weekly liquidity and 1 if the hedge fund's restriction period is longer than two weeks; $\Delta$ Leverage is the difference between the average

\footnotetext{
${ }^{47}$ The regression model framework we use closely follows that of Cao, Farnsworth, Liang, and Lo (2013), who examine the difference in returns between a hedge fund and its Separate Account Platform share class.
} 
leverage of the hedge fund and that of the UCITS pair; and $\Delta$ Controls is the difference between hedge funds and UCITS share classes for the set of control variables defined previously in Table 7. Finally, we control for strategy and time fixed effects and, following Petersen (2009), adjust standard errors within firm-level cluster correlation.

Panel A of Table 9 reports the results for companies that manage both hedge funds and UCITS funds. There is evidence that share and leverage restrictions are driving the difference between UCITS and non-UCITS share classes. We find a positive and statistically significant coefficient for differences in the restriction dummy, which means that hedge funds should outperform their UCITS counterparts that have shorter restriction periods. The economic magnitude of performance difference is large, being $1.80 \%-2.16 \%$ per annum. We also find evidence that the level of leverage matters.

\section{[[ Insert Table 9 about here ]]}

Panel B of the table presents a test in which we control for the selectivity bias associated with the fund manager's ability. The concern is that management companies put their best managers to hedge funds because of the possibility to earn higher fees. Using a sample of individuals who manage both UCITS and non-UCITS fund, we investigate the effect of regulatory constraints on fund performance so that we can control for fund manager skill; this procedure should yield cleaner estimates of such regulatory constraints as share restrictions and leverage limits, because they are not contaminated due to selectivity bias. Using a sample obtained from the EurekaHedge database, we repeat the analysis from Panel A but now for pairs of comparable funds run by the same manager (not the same management company). The results, which are reported in Panel B, support our earlier conclusions. We find a positive and significant coefficient for the restriction dummy and also for leverage differences. Hence these results support our Liquidity Restriction Hypothesis even after we control for the role of firm-level effects and fund manager skill.

\section{Performance Persistence Hypothesis}

Our Persistence Hypothesis in Section 2 states that ARUs should exhibit less performance persistence than other HFs because the latter's trading strategies are more secretive. However, exploiting any performance persistence in hedge funds may be hampered by various share restrictions. Hedge funds 
normally restrict capital withdrawals by imposing lockup, advance notice, and redemption periods. Such restrictions prevent investors from withdrawing capital from hedge funds in a timely fashion. In contrast, ARUs are required to provide investors with at least bi-weekly liquidity. Thus real-world HF investors may be unable to exploit any short-term performance persistence even as ARU investors can frequently rebalance their portfolios. It is worth noting, however, that a significant proportion of HFs do provide rebalancing options similar to those available for ARUs. We are therefore interested in examining whether redemption restrictions hamper the exploitation by investors of short-term performance persistence.

Glode and Green (2011) explain the performance persistence of hedge funds by showing that it could reflect a desire for secrecy. As mentioned previously, these authors point out that superior returns may be due only partly to manager ability; such returns might also be attributable to strategies or techniques that could be expropriated and exploited by informed others. Arguments like this are consistent with a competitive economy's "zero-profit" condition, under which enough money chasing a given pattern in returns will necessarily eliminate that pattern. Therefore, our Performance Persistence Hypothesis predicts that the performance of HFs will be more persistent than that of ARUs.

We use a standard methodology to compare the performance persistence of HFs and ARUs. In the spirit of Carhart (1997), we sort funds into quintile portfolios based on their past (9-factor alpha) $t$ statistics, which are estimated over the prior two years' data. The alpha $t$-statistic's superior predictive power is such that we expect it to reveal greater performance persistence than would a simple sort by fund alpha. ${ }^{48}$ We use different portfolio rebalancing periods that range from a month to a year in length, and we calculate returns for each of the quintile portfolios across these rebalancing horizons. ${ }^{49}$ Then we estimate the alpha spread between the top- and bottom-quintile portfolios.

\section{[[ Insert Figure 3 about here ]]}

Figure 3 plots results, across the rebalancing horizons, from our tests for performance persistence. We find that, whereas HF performance persists, ARUs do not deliver long-term performance persistence. This evidence is supportive of the Persistence Hypothesis. Our findings also

\footnotetext{
${ }^{48}$ Funds with a short history of monthly net returns will tend to generate alphas that are outliers. The alpha $t$-statistic corrects for outliers by normalizing the fund alpha in terms of its estimated precision (Kosowski, Timmermann, Wermers, and White 2006; Kosowski, Naik, and Teo 2007).

${ }^{49}$ The portfolios are equal-weighted monthly, so weights are re-adjusted whenever a fund disappears.
} 
suggest that, although HFs providing at least bi-weekly liquidity exhibit considerable performance persistence during the sample period, HFs that impose a lockup period as well as notice and redemption periods exceeding 30 days do not deliver significant performance persistence on an annual basis. $^{50}$

\section{[[ Insert Figure 4 about here ]]}

Given that all ARUs and some HFs allow investors the option of redeeming their capital in a timely fashion, we conduct some performance persistence tests. For this purpose, we form out-ofsample strategies by using an alpha $t$-statistic that is lagged by one month; this procedure reflects the capacity of a real-time investor to rebalance her portfolio. The results of these tests are graphed in Figure 4, which shows significant performance persistence for (liquid) HFs but none for ARUs. In short: HF performance persists, but ARUs cannot deliver significant performance persistence even at monthly horizons.

\section{Conclusion}

This paper contributes on the literature on the effect of regulation, geography and liquidity on asset price performance and welfare by documenting the effect of geographically disparate hedge fund regulation on fund performance. Based on regulatory constraints, such as reporting and risk management requirements, constraints on the investment opportunity set, requirements and share restrictions, we economically motivate and test a range of hypotheses regarding differences in performance and risk between Absolute Return UCITS (ARUs) and hedge funds. On the one hand, we find strong support for our Misvaluation Hypothesis since ARUs funds exhibit significantly less suspicious return patterns. One the other hand, we do not find support for the Operational Risk Hypothesis since ARUs funds have higher operational risk metrics than hedge funds. Restrictions on the investment opportunity set seem to have economically significant impact on risk-adjusted performance, since consistent with the Performance Hypothesis we find robust evidence of lower riskadjusted performance for ARUs than hedge funds. Despite the UCITS directives focus on risk management it seems that restrictions on derivatives and short-selling have a material impact on fund

\footnotetext{
${ }^{50}$ Appendix Tables B5 and B6 report the statistical differences for alphas as well as a wide range of other performance measures.
} 
risk, since in the context of the Risk Hypothesis, we find that hedge funds generally exhibit lower volatility and less tail risk than do ARUs, which is consistent with the difficulty of porting the risk management techniques of hedge funds to the ARU domain. In the context of our tests of the Liquidity Restrictions hypothesis, we uncover a strong performance-liquidity tradeoff. Although ARUs underperform other hedge funds on average, comparing ARU and HF groups that are liquidity-matched (in terms of share restrictions) shows that the performance of these two fund types converges. Finally, in our tests of the Persistence Hypothesis, we establish that there are limits to the ability of an investor to exploit the superior liquidity of ARUs because they exhibit less performance persistence than do some hedge funds.

There are two additional reasons why UCITS and ARUs are likely to attract the attention of researchers. First, both fund universes are growing rapidly and have become of increasing economic importance. Second, the latest UCITS rules impose remuneration caps on managers of UCITS funds, including UCITS hedge funds, and these rules can be expected to affect fund performance.

An interesting area for future research would be to examine the performance of US ' 40 Act funds and compare them to a matched sample of similar funds within the same management company. Domicile effects also warrant additional research, and we remark that the subsample of QIFs and SIFs domiciled in (respectively) Luxembourg and Ireland face restrictions that are less stringent than those of UCITS yet are more stringent than those typically governing offshore funds. Comparing the performance of QIF and SIF funds with other hedge funds would illuminate the effect of domicile on performance and risk. 


\section{References}

Agarwal, V., Boyson, N. M. and N. Naik, 2009. Hedge Funds for Retail Investors? An Examination of Hedged Mutual Funds, Journal of Financial and Quantitative Analysis, Vol.44, No.2, Apr. 2009, pp. 273-305.

Agarwal, V., Daniel N. D., and Naik N. Y., 2009. Role of managerial incentives and discretion in hedge fund performance. The Journal of Finance 64(5), 2221-2256.

Agarwal, V., Daniel N. D., and Naik N. Y., 2011. Do hedge funds manage their reported returns? Review of Financial Studies, 24(10), 3281-3320.

Agarwal, V. Jiang W-, Tang Y., and Yang B., 2013. Uncovering hedge fund skill from the portfolio holdings they hide. Journal of Finance, 68(2), 739-783.

Agarwal, V., and Naik, N.Y., 2000. Multi-period performance persistence analysis of hedge funds. Journal of Financial and Quantitative Analysis 53, 327-342.

Agarwal, V., and Naik, N.Y., 2004. Risks and Portfolio Decisions Involving Hedge Funds, Review of Financial Studies, 17(1), 63-98.

Aggarwal, R., K. and Jorion, P., 2010. The performance of emerging hedge funds and managers. Journal of financial economics. 96, 238-256.

Aiken A. L., Clifford C. P. and Ellis J. A. 2014. Hedge Funds and Discretionary Liquidity Restrictions, Forthcoming Journal of Financial Economics

Almazan, A., Brown, K.C. Carlson, M. and Chapman D.A., 2004. Why Constrain your Mutual Fund Manager? Journal of Financial Economics, 73, 289-321.

Amihud, Y., and Mendelson H., 1986. Asset pricing and the bid-ask spread, Journal of Financial Economics, 17(2), 223-249.

Amihud, Y., Mendelson H., and Pedersen L. H., 2006. Liquidity and asset prices. Foundations and Trends in Finance 1(4), 269-364.

Aragon, G. O., 2007. Share restrictions and asset pricing: Evidence from the hedge fund industry. Journal of Financial Economics 83(1), 33.58.

Aragon, G. O. Liang, B., and Park H., 2013. Onshore and offshore hedge funds: Are they twins? Forthcoming in Management Science.

Aragon, G. O. and Spencer Martin, J., 2012. A unique view of hedge fund derivatives usage: Safeguard or speculation? Journal of Financial Economics, 105(2), 436-456.

Asness C., Frazzini A., and Pedersen L.H., 2013. Quality minus junk. Working paper. 
Bali, T.G., Brown, S.J. and Caglayan, M. O., 2012, Systematic risk and the cross section of hedge fund returns, Journal of Financial Economics 106 (1), 114-131.

Banegas, A., Gillen, B., Timmermann, A. and Wermers, R., 2013. The cross section of conditional mutual fund performance in European stock markets. Journal of Financial Economics 108(3), 699-726.

Bollen, N. P., and Pool, V. K., 2008. Conditional return smoothing in the hedge fund industry, Journal of Financial and Quantitative Analysis 43, 267-298.

Bollen, N.P., Pool, V.K., 2009. Do hedge fund managers misreport returns? Evidence from the pooled distribution, Journal of Finance 64, 2257-2288.

Bollen, N.P., and V.K. Pool. 2012. Suspicious patterns in hedge fund returns and the risk of fraud. Review of Financial Studies 25, 2673-2702.

Brav, A., Jiang, W., Partnoy, F., and R. Thomas, 2008, Hedge Fund Activism, Corporate Governance, and Firm Performance, Journal of Finance 63(4).

Brown S., W. Goetzmann, B. Liang, and C. Schwarz, 2008. Mandatory Disclosure and Operational Risk: Evidence from Hedge Fund Registration, Journal of Finance, 63(6), pp. 2785- 2815.

Brown S., W. Goetzmann, B. Liang, and C. Schwarz, 2009. Estimating Operational Risk for Hedge Funds: The $\Omega$-Score, Financial Analysts Journal, 65(1), pp. 43-53.

Brown S., W. Goetzmann, B. Liang, and C. Schwarz, 2012. Trust and Delegation, Journal of Financial Economics, 103(1), pp. 221-234.

Buraschi, A., Kosowski, R. and Sritrakul, W., 2014. Incentives and Endogenous Risk Taking: A Structural View of Hedge Funds Alphas. Forthcoming at Journal of Finance.

Cao, C., Chen, Y., Liang, B., and Lo, A., 2013. Can hedge funds time market liquidity? Journal of Financial Economics, 109(2), 493-516.

Cao, C., Farnsworth, G. V., Liang, B. and Lo, A. W., 2013. Liquidity costs, return smoothing, and investor flows: Evidence from a separate account platform. Working Paper.

Carhart, M (1997). On persistence in mutual fund performance. Journal of Finance, 52, 57-82.

Cassar, G., Gerakos J., 2010. Determinants of hedge fund internal controls and fees. The Accounting Review 85 (6), 1887-1919.

Cassar, G., Gerakos J., 2011. Hedge funds: pricing controls and the smoothing of self-reported returns. Review of Financial Studies, 24, 1698-1734

Cassar, G., Gerakos J., 2013. Does risk management work? University of Chicago. 
Cici G., Gibson S., Moussawi R., 2010. Mutual fund performance when parent firms simultaneously manage hedge funds. Journal of Financial Intermediation 19(2), 169-187

Cohen, R. B. and Polk, C. and Silli, B., 2010, Best Ideas, Available at SSRN: http://ssrn.com/abstract=1364827.

Coval, J. and T. Moskowitz, 2001. The geography of investment: informed trading and asset prices. Journal of Political Economy, 4, 811-841.

Darolles, S., 2011. Quantifying Alternative UCITS, Working Paper.

Deuskar P., Pollet J.M., Wang Z.J., and Zheng L. 2011. The good or the bad? Which mutual fund managers join hedge funds? Review of Financial Studies 24 (9), 3008-3024

Ding B., Getmansky M., Liang B., and Wermers R., 2008. Investor flows and share restrictions in the hedge fund industry. Working paper.

Frazzini A. and L.H. Pedersen (2014). Betting Against Beta, Journal of Financial Economics, 111, 125.

Fung, W., Hsieh, D., 2000. Performance characteristics of hedge funds and CTA funds: Natural versus spurious biases. Journal of Financial and Quantitative Analysis 35, 291-307.

Fung, W., Hsieh, D., 2004. Hedge fund benchmarks: a risk based approach. Financial Analyst Journal $60,65-80$.

Fung, W. and Hsieh D., 2009. Measurement biases in hedge fund performance data: An update, Financial Analysts Journal 65, 36-38.

Getmansky, M., Lo A., and Makarov I., 2004. An econometric model of serial correlation and illiquidity of hedge fund returns. Journal of Financial Economics. 74, 529-610.

Glode, V., Green, R. C., 2011. Information spillovers and performance persistence for hedge funds. Journal of financial economics. 101, 1-17.

Goetzmann W., Ingersoll J., Spiegel M., and Welch I., 2007. Portfolio performance manipulation and manipulation-proof performance measures. Review of Financial Studies 20 (5), 1503-1546.

Heckman J.J, 1987. Sample selection bias as a specification error. Econometrica, 153-161.

Ineichen, A. 2006. Asymmetric Returns: Future of Active Asset Management, Wiley.

Joenväärä, J., Kosowski, R., and Tolonen, P., 2014. Hedge fund performance: What do we know? Imperial College Business School.

Jones, C. M. and Reed, A. V. and Waller, W., 2015, Revealing Shorts: An Examination of Large Short Position Disclosures, Available at SSRN: http://ssrn.com/abstract=1910372. 
Jorion, P. and Schwarz, C., 2014. Are hedge fund managers systematically misreporting? Or not? Journal of Financial Economics 111 (2), 311-327

Koski J., and Pontiff J., 1999. How are derivatives used? Evidence from the mutual fund industry, Journal of Finance 54, 791-816.

Kosowski, R., Naik N. Y., and Teo M., 2007. Do hedge funds deliver alpha? A Bayesian and bootstrap analysis. Journal of Financial Economics 84(1), 229.264.

Kosowski, R., A. Timmermann, R. Wermers, and H. White (2006). Can mutual fund "stars“ really pick stocks? New evidence from a bootstrap analysis. The Journal of Finance 61(6), 2551-2595.

Liang, B., 2000. Hedge funds: The living and the dead. Journal of Financial and Quantitative Analysis 35(3), 309.326.

Lustig, H., N. Roussanov and A. Verdelhan. (2011). Common Risk Factors in Currency Markets. Review of Financial Studies. 24 (11), 3731-3777.

Malloy, C. 2005. The geography of equity analysis. Journal of Finance 60, 719-755.

Newey, W., West, K., 1987. A simple, positive semi-definite, heteroscedasticity and autocorrelation consistent covariance matrix. Econometrica 55, 703-708.

Nohel, T., Wang, Z., Zheng, L. 2010. Side-by-side management of hedge funds and mutual funds. Review of Financial Studies, 23: 2342-2373

Pastor, L. and R. F. Stambaugh (2003). Liquidity risk and expected stock returns. Journal of Political Economy $111(3), 642-685$.

Ramadorai T. 2012. The secondary market for hedge funds and the closed hedge fund premiu, Journal of Finance, 67, 479-512.

Ramadorai T. 2013. Capacity constraints, investor information, and hedge fund returns 2013, Journal of Financial Economics, 107, 401-416.

Patton, A. J., 2009, Are 'Market Neutral' Hedge Funds Really Market Neutral? Review of Finanical Studies. 22 (7), 2495-2530.

Patton, A. J. and A. Timmermann (2010). Monotonicity in asset returns: New tests with applications to the term structure, the CAPM, and portfolio sorts. Journal of Financial Economics 98, 605-625.

Petersen M. A., 2009. Estimating standard errors in finance panel data sets: Comparing approaches Review of financial studies 22 (1), 435-480

Sadka, R., 2010. Liquidity risk and the cross-section of hedge-fund returns, Journal of Financial Economics, 98(1), 54-71. 
Stefanini, F., Derossi, T., Meoli, M. and S., Vismara (2010). Newcits: Investing in UCITS Compliant Hedge Funds, Wiley Finance Series, First Edition.

Teo, M., 2010. Does size matter in hedge fund industry? SMU - School of Business.

Teo, M., 2011. The Liquidity Risk of Liquid Hedge Funds, Journal of Financial Economics, 100, 2444.

Titman, S. and C. I. Tiu (2011). Do the best hedge funds hedge? Review of Financial Studies 24(1), 123-168.

Tuchschmid, N.S., Wallerstein, E. and L., Zanolin (2010). Will Alternative UCITS Ever be Loved Enough to Replace Hedge Funds, working paper, Haute Ecole de Gestion de Genève. http://ssrn.com/abstract=1686055. 


\section{Figure 1. Proportion of funds across fund domiciles}

This pie graph shows the fund domicile distribution of the absolute returns on UCITS funds (Panel A) and on all funds (Panel B) as of June 2013.

\section{Panel A: Absolute returns on UCITS funds}

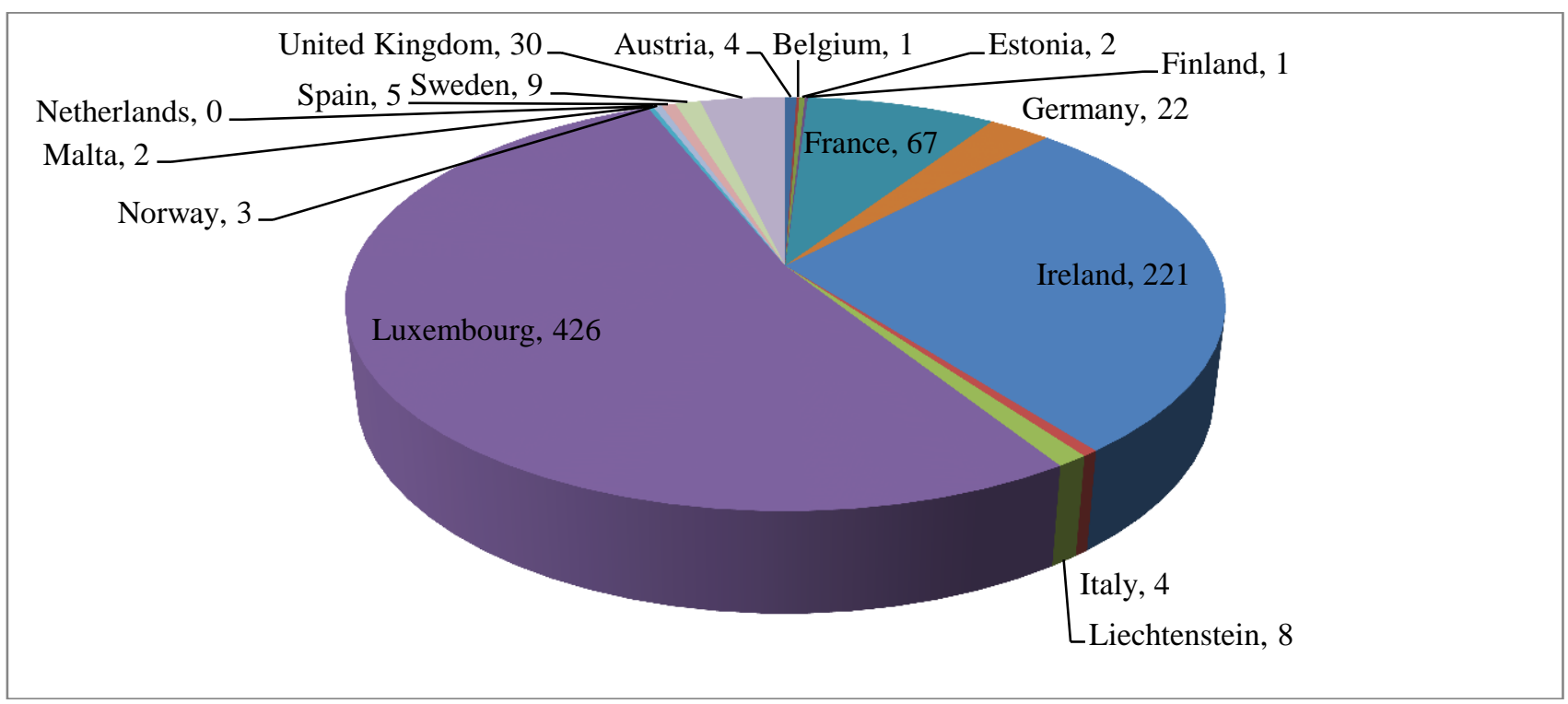

Panel B: Absolute returns on all funds

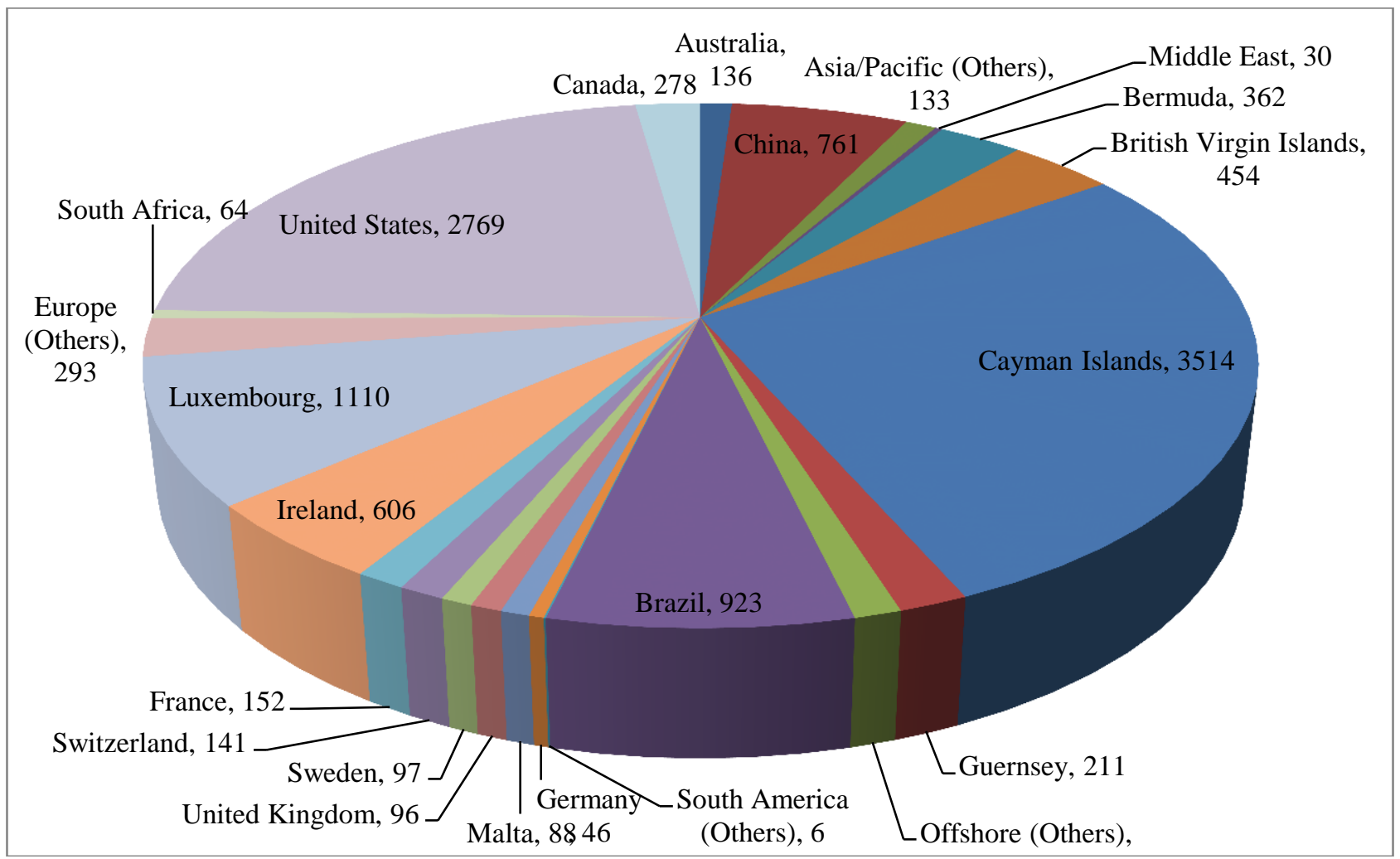




\section{Figure 2. Summary Statistics}

This bar graph illustrates the strategy distribution (Panel A), AuM invested in geographic regions (Panel B), and fund size distribution (Panel C) across fund domiciles.

Panel A: Investment strategy distribution across fund domiciles

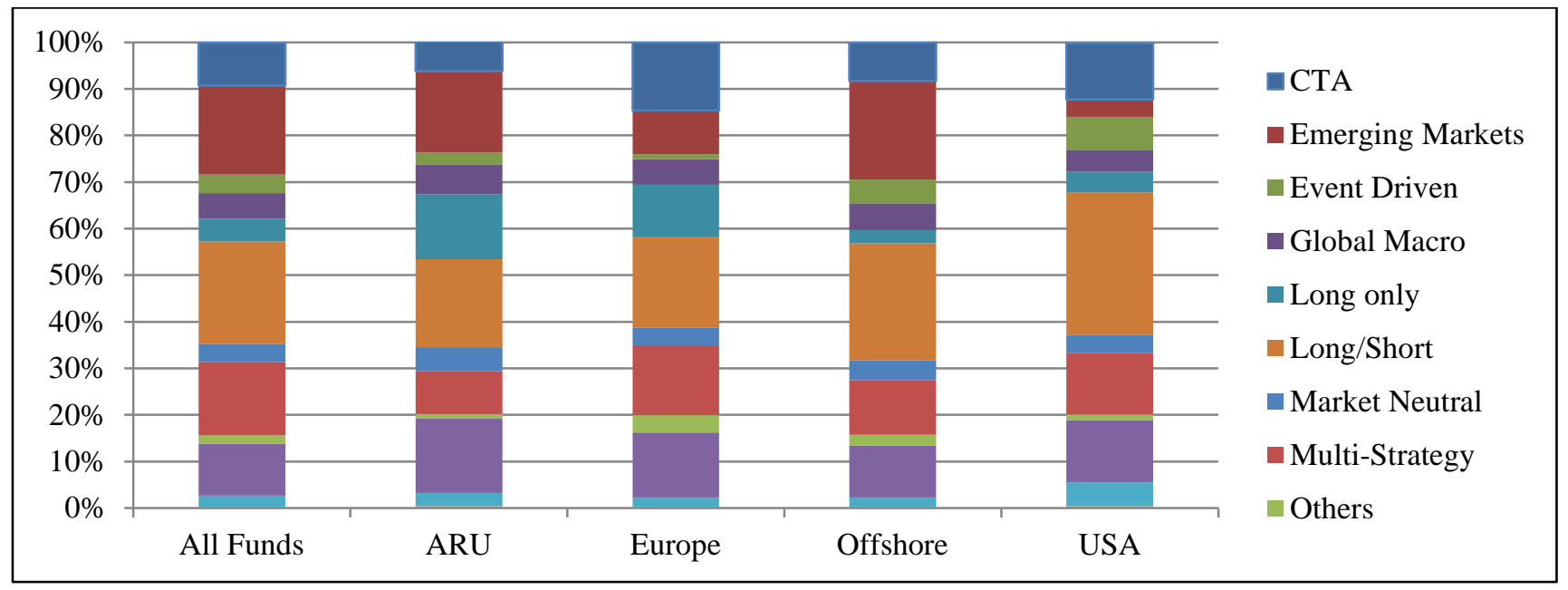

Panel B: Proportion of AuM invested in geographic regions

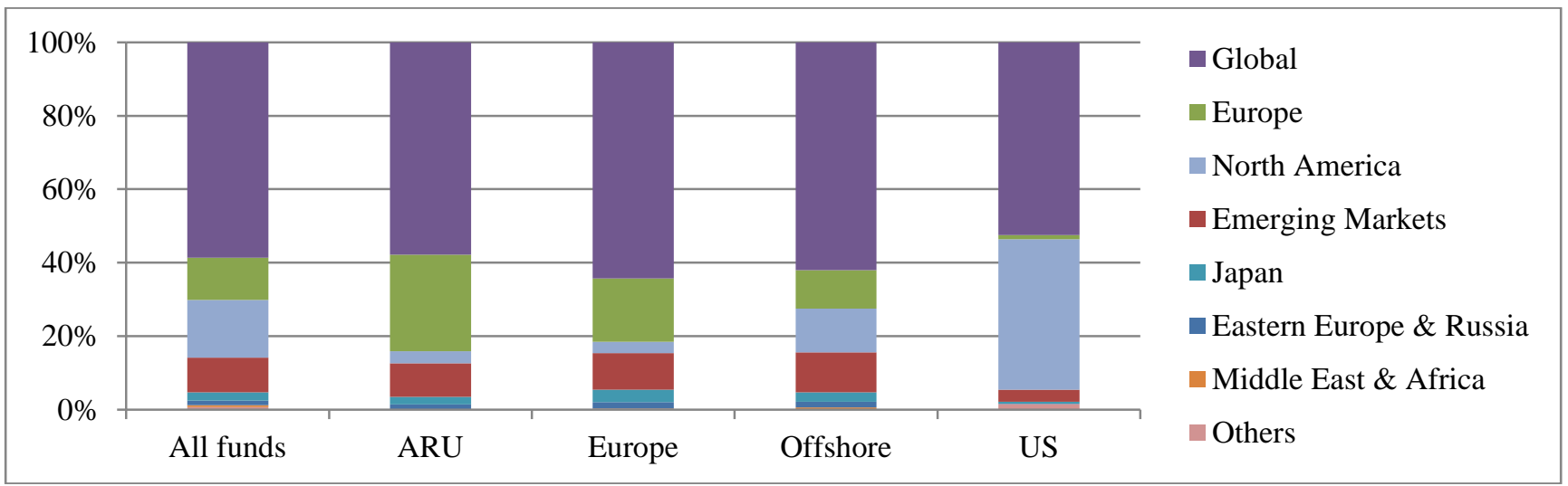

Panel C: Fund size distribution across fund domiciles

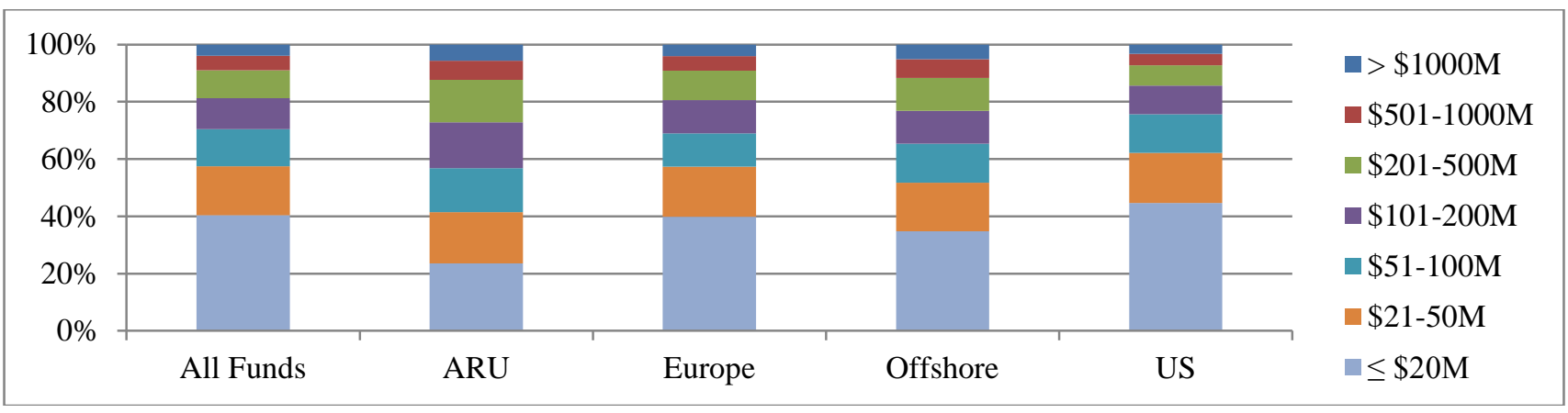




\section{Figure 3. Performance persistence differences between ARUs and HFs}

This figure plots the (annualized) 9-factor Fung-Hsieh (FH) alphas for the ARUs and HFs. It displays the top and bottom quintile alphas across rebalancing frequencies. Using $t$-statistics of the nine-factor FH alpha, funds are sorted into quintile portfolios that are rebalanced at $1,2,3,4,6$ and 12 months frequencies. The $t$-statistics are estimated using the 24 most recent return observations.

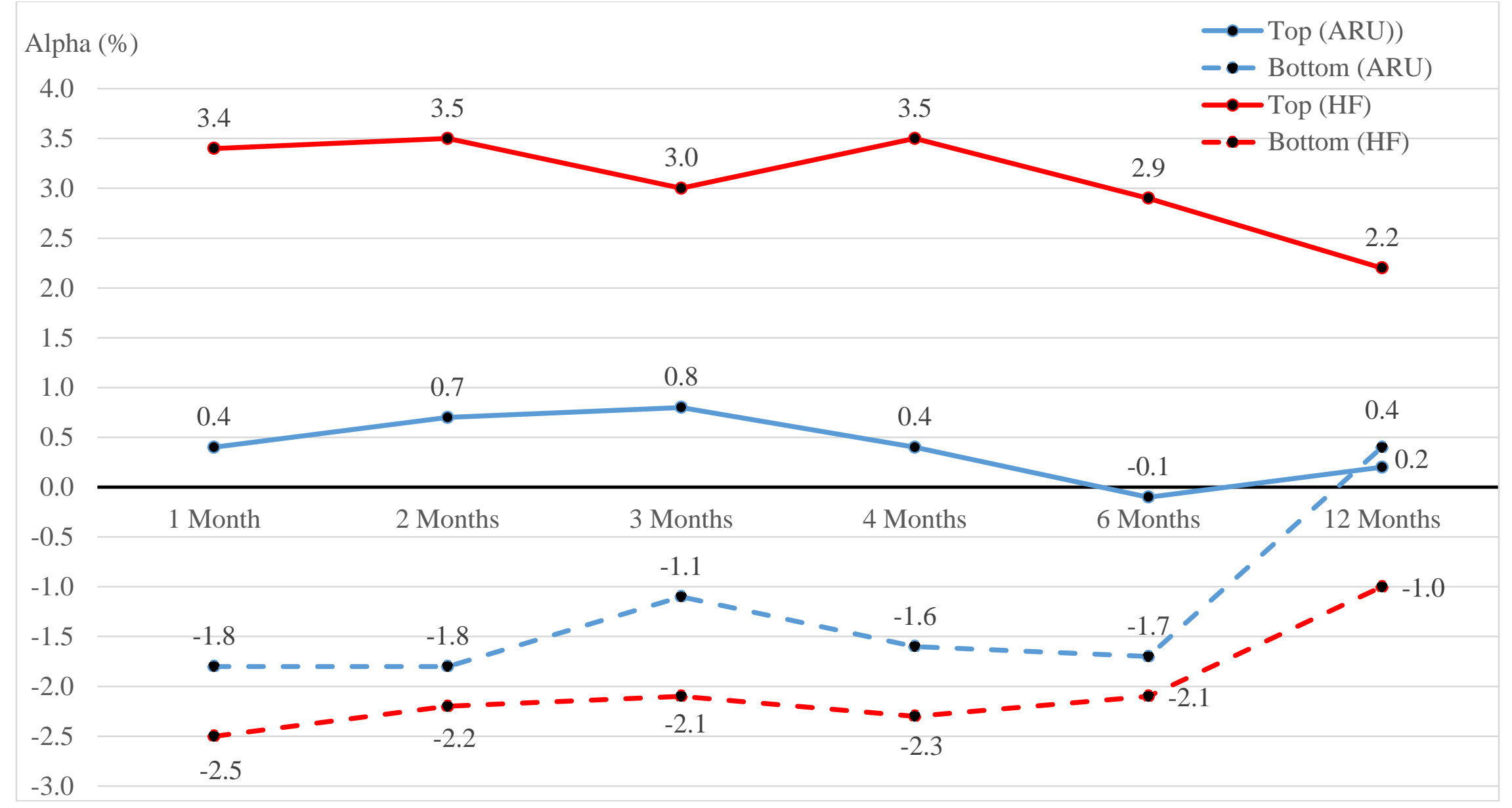




\section{Figure 4. Feasibility and Performance Persistence}

This figure plots the (annualized) 9-factor FH alphas for the ARUs and HFs. We control for Figures displays the top and bottom quintile alphas across rebalancing frequencies. Using $t$-statistics of the nine-factor FH alpha, funds are sorted into quintile portfolios that are rebalanced at 1, 2, 3 , 4, 6 and 12 months frequencies. The $t$-statistics are estimated using the 24 most recent return observations.

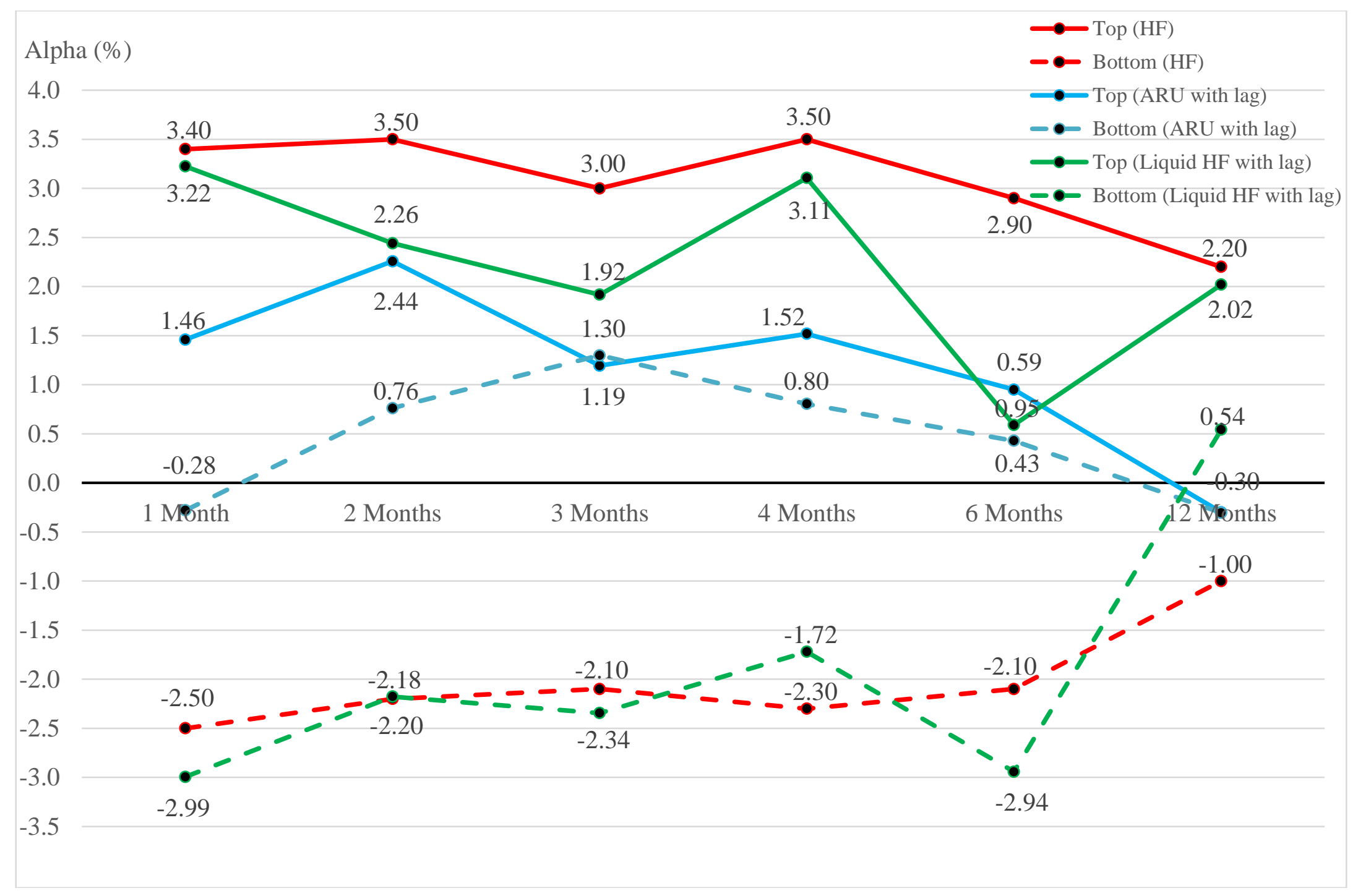




\section{Table 1: Capital formation of Hedge Funds and Absolute Return UCITS}

This table presents the capital formation process of hedge funds and Absolute Return UCITS from December 2003 to December 2012. $N$ is the number of funds in given year. 'AuM' provides aggregate assets under management for Hedge Funds and Absolute Return UCITS. 'Attrition rate' is the percentage of funds that became inactive during the year.

\begin{tabular}{cccccccc} 
& \multicolumn{3}{c}{ Hedge Funds } & & \multicolumn{3}{c}{ Absolute Return UCITS } \\
\cline { 2 - 3 } Year & $\mathrm{N}$ & AuM & Attrition rate & & $\mathrm{N}$ & AuM & Attrition Rate \\
\hline 2003 & 10,081 & 895,585 & 5.2 & & 144 & 5,835 & 0 \\
2004 & 11,991 & $1,344,230$ & 5.9 & & 180 & 11,365 & 0 \\
2005 & 13,621 & $1,599,562$ & 7.8 & & 229 & 22,301 & 0 \\
2006 & 14,972 & $2,119,883$ & 9.1 & & 301 & 48,216 & 0.7 \\
2007 & 15,891 & $2,666,225$ & 10.6 & & 381 & 62,941 & 0.8 \\
2008 & 15,190 & $1,832,842$ & 17.1 & & 466 & 38,298 & 1.7 \\
2009 & 14,936 & $1,828,022$ & 13.0 & & 618 & 78,892 & 1.1 \\
2010 & 14,801 & $1,992,104$ & 12.5 & & 801 & 137,382 & 3.7 \\
2011 & 14,403 & $2,028,704$ & 12.9 & & 878 & 177,347 & 8.6 \\
2012 & 13,044 & $1,981,433$ & 16.1 & & 854 & 226,485 & 12.0 \\
\hline
\end{tabular}




\section{Table 2: Summary Statistics of Fund Characteristics}

The right hand-side of this table presents the summary statistics for fund size and age as well as compensation and share restrictions variables of Hedge Funds (HF) and Absolute Return UCITS (ARU). The left hand-side presents fund characteristics across hedge fund domicile. The table presents cross-sectional difference tests for each fund characteristics. 'Size' denotes the fund's size in millions of US dollars. 'Age' denotes the fund's age in years based on the fund inception data. 'Management Fee' shows the management fee within a specific category. 'Incentive Fee' denotes the performance-based fee that fund charges. 'High-water Mark' indicates whether a fund imposes a high-water mark provision. 'Redemption' denotes redemption frequency. 'Notice' is the advance notice period. 'Restriction' is the sum of redemption and notice periods. 'Lockup' denotes the length of period when investors are restricted to withdraw their initial investment. 'Lockup Dummy' denotes the proportion of funds imposing a lockup period. 'Minimum Investment' is the fund's minimum subscription amount in US dollars. 'Leverage Dummy' reports to proportion of funds that use leverage. 'Average Leverage 'is the amount of average leverage.

\begin{tabular}{lcccc} 
& \multicolumn{4}{c}{ Mean difference between ARUs and HFs } \\
& ARU & HF & Diff & $t$-statistic \\
\hline Size & 246.02 & 162.98 & 83.04 & 3.15 \\
Age & 4.82 & 6.31 & -1.49 & -10.28 \\
Management Fee & 1.29 & 1.54 & -0.24 & -13.35 \\
Incentive Fee & 12.38 & 17.66 & -5.29 & -19.99 \\
High-water Mark & 0.6 & 0.72 & -0.11 & -7.73 \\
Redemption & 2.3 & 57.76 & -55.45 & -122.33 \\
Notice & 1.42 & 30.85 & -29.43 & -143.47 \\
Lockup & 0 & 89.23 & -89.23 & -77.27 \\
Lockup Dummy & 0 & 0.25 & -0.25 & -96.62 \\
Minimum Investment & 0.49 & 2.05 & -1.56 & -5.71 \\
& & & & \\
Average Leverage & 31.48 & 57.71 & -26.23 & -7.98 \\
Leverage Dummy & 0.33 & 0.52 & -0.19 & -12.97 \\
\hline
\end{tabular}

\begin{tabular}{ccc}
\multicolumn{3}{c}{ Hedge Fund Domicile } \\
Europe & Offshore & USA \\
\hline 194.84 & 202.02 & 129.76 \\
5.22 & 6.54 & 7.38 \\
1.50 & 1.59 & 1.51 \\
14.86 & 18.10 & 18.81 \\
0.59 & 0.82 & 0.69 \\
24.32 & 49.22 & 87.60 \\
13.00 & 36.38 & 33.49 \\
21.14 & 70.17 & 151.86 \\
0.05 & 0.19 & 0.41 \\
1.32 & 1.77 & 2.29 \\
& & \\
56.40 & 69.73 & 45.62 \\
0.43 & 0.59 & 0.45 \\
\hline
\end{tabular}




\section{Table 3: Suspicious Patterns in Reported Returns}

This table compares suspicious patterns in reported returns of absolute return UCITS (ARU) and hedge funds (HF) across domiciles (Europe, Offshore and USA). We require that each fund has at least 24 return observations over the period from January 2005 to June 2012 . A set of used measures is based on Bollen and Pool (2012). Greater manipulation in reported returns are indicated by + or - sigs. Table reports the crosssectional means and their difference tests. Panel A reports the asset liquidity proxy. 'Autocorrelation' refers to the test statistic of the first-order coefficient in a MA(1) model of returns. Panel B reports discontinuity in the distribution of returns proxy. 'Kink' refers to the test statistic of the kink flag, measuring the abnormal rate of reporting small losses. Panel C reports two measures of low correlation. 'Index $\mathrm{R}^{2}$ ' is the $p$-value of the slope coefficient from a regression of fund returns on a corresponding style index. 'Max $\mathrm{R}^{2}$ ' refers to the adjusted $R$-square of fund returns against the seven Fung-Hsieh (2004) factors and the four Agarwal-Naik (2000) factors. Panel D reports four measures of data-quality. '\% Repeat' is triggered by a high number of returns that are repeated. '\# Zero' refers to the number of zero returns. '\% Negative' refers to the fraction of negative returns. 'Uniform' refers to the test statistic of the uniformity of the last digit in reported returns. 'PC Misvalution' is the $1^{\text {st }}$ principal component of the Bollen-Pool (2012) 'red flags'.

Panel A: Asset liquidity

\begin{tabular}{|c|c|c|c|c|c|c|c|c|}
\hline & \multirow[b]{2}{*}{ Manipulation } & \multirow[b]{2}{*}{$\mathrm{HF}$} & \multirow[b]{2}{*}{ ARU } & \multirow[b]{2}{*}{ Difference } & \multirow[b]{2}{*}{$t$-statistic } & \multicolumn{3}{|c|}{ Hedge Fund Domicile } \\
\hline & & & & & & Europe & Offshore & USA \\
\hline Autocorrelation & + & 0.96 & 0.26 & 0.70 & 15.17 & 0.58 & 1.20 & 1.02 \\
\hline
\end{tabular}

Panel B: Discontinuity in the distribution of fund returns

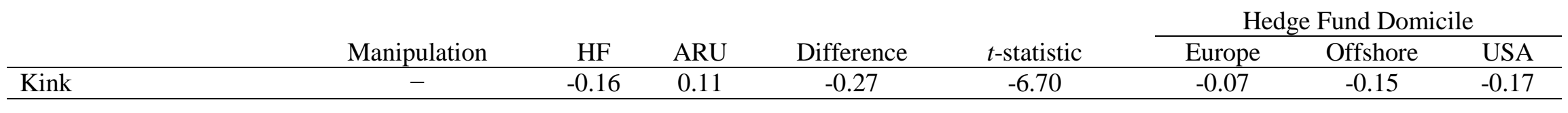

Panel C: Measures of low correlation between fund returns and the returns of style factors

\begin{tabular}{|c|c|c|c|c|c|c|c|c|}
\hline & \multirow[b]{2}{*}{ Manipulation } & \multirow[b]{2}{*}{$\mathrm{HF}$} & \multirow[b]{2}{*}{ ARU } & \multirow[b]{2}{*}{ Difference } & \multirow[b]{2}{*}{$t$-statistic } & \multicolumn{3}{|c|}{ Hedge Fund Domicile } \\
\hline & & & & & & Europe & Offshore & USA \\
\hline Index $R^{2}$ & + & 0.09 & 0.02 & 0.07 & 17.47 & 0.06 & 0.08 & 0.13 \\
\hline $\operatorname{Max} R^{2}$ & - & 0.43 & 0.57 & -0.14 & -22.15 & 0.46 & 0.41 & 0.44 \\
\hline
\end{tabular}


Panel D: Family of data-quality indicators

\begin{tabular}{lcccccccc} 
& & & & & & \multicolumn{2}{c}{ Hedge Fund Domicile } \\
\cline { 3 - 8 } & Manipulation & HF & ARU & Difference & $t$-statistic & Europe & Offshore & USA \\
\hline \% Repeat & + & 0.03 & 0.01 & 0.02 & 6.18 & 0.03 & 0.03 & 0.03 \\
\# Zero & + & 0.38 & 0.27 & 0.11 & 3.59 & 0.58 & 0.41 & 0.30 \\
\% Negative & - & 0.38 & 0.42 & -0.04 & -11.77 & 0.41 & 0.38 & 0.38 \\
Uniform & + & 16.81 & 15.79 & 1.02 & 4.25 & 16.29 & 16.75 & 17.33 \\
\hline
\end{tabular}

Panel E: Combining proxies of suspicious reported returns

\begin{tabular}{|c|c|c|c|c|c|c|c|c|}
\hline & \multirow[b]{2}{*}{ Manipulation } & \multirow[b]{2}{*}{ HF } & \multirow[b]{2}{*}{ ARU } & \multirow[b]{2}{*}{ Difference } & \multirow[b]{2}{*}{$t$-statistic } & \multicolumn{3}{|c|}{ Heage rund Dommene } \\
\hline & & & & & & Europe & Offshore & USA \\
\hline PC Misvaluation & + & 0.01 & -0.30 & 0.31 & 11.02 & -0.09 & 0.02 & 0.01 \\
\hline
\end{tabular}




\section{Table 4: Past Violations and Conflicts of Interest}

This table compares the operational risk measures and their sources of hedge funds and absolute return UCITS. Panel A reports operational risk measures. Panel B (Panel C) report a set of proxies for the external (internal) conflicts of interest. We report results separately across hedge funds domiciles. 'ADV-filers (\%)' is the portion of funds file ADV for SEC. 'Problem Funds (\%)' refers to funds that answered Yes to at least one question in Item 11 of ADV filing. Item 11 identifies any "problems" that the management or related advisory affiliates have, including felonies, investment-related misdemeanors or any agency, SEC, CFTC, or self-regulatory issues, regulatory disciplinary action as well as civil lawsuits. 'Omega score' is the Brown, Goetzmann, Liang and Schwarz (2008, 2009) operational risk measure. Estimation of Omega is described in Appendix.. 'Broker/Dealer' is 1 if the fund has a related broker/dealer. 'Investment Adviser', 'Commodities Broker', 'Bank', 'Insurance' and 'Sponsor of LLP' are 1 if the fund is related to one of these companies respectively. 'BuySellYourOwn' is 1 if the company buys and sells between itself and clients. 'BuySellYourselfClients' is 1 if a related party buys and sells securities also recommended to the fund. 'RecSecYouOwn' is 1 if the fund recommends securities in which a related party has an ownership interest. 'AgencyCrossTrans' is 1 if the fund performs agency cross transactions. 'RecUnderwriter' is 1 if a related party recommends securities to clients for which they are the underwriter. 'RecSalesInterest' is 1 if a related party recommends securities with a sales interest. 'RecBrokers' is 1 if a related party recommends. 'OtherResearch' is 1 if the fund uses external research. Frequency of conflicts is the total sum of conflicts within a specific category. 'PC External Conflicts' is the $1^{\text {st }}$ principal component of external conflicts of interest variables. 'PC Internal Conflicts' is the $1^{\text {st }}$ principal component of external conflicts of interest variables. 'PC Conflicts' is the $1^{\text {st }}$ principal component of conflicts of interest variables.

Panel A: Problem Funds and Operational Risk

\begin{tabular}{lccccccccc} 
& \multicolumn{4}{c}{ All Funds } & & \multicolumn{3}{c}{ Hedge Fund Domicile } \\
\cline { 2 - 4 } & ARU & HF & Diff & $t$-statistic & & Europe & Offshore & USA \\
\hline ADV-filers (\%) & 0.24 & 0.26 & -0.02 & -1.47 & & 0.17 & 0.31 & 0.31 \\
Problem funds (\%) & 0.40 & 0.27 & 0.13 & 3.69 & & 0.45 & 0.29 & 0.18 \\
Omega score & 0.33 & 0.25 & 0.09 & 24.05 & & 0.28 & 0.26 & 0.21 \\
\hline
\end{tabular}

Panel B: External Conflicts of Interest

\begin{tabular}{|c|c|c|c|c|c|c|c|}
\hline \multirow[b]{3}{*}{ With: } & \multicolumn{4}{|c|}{ All Funds } & \multicolumn{3}{|c|}{ Hedge Fund Domicile } \\
\hline & \multicolumn{2}{|c|}{$\%$ Yes } & \multirow[b]{2}{*}{ Diff } & \multirow[b]{2}{*}{$t$-statistic } & \multicolumn{3}{|c|}{$\%$ Yes } \\
\hline & ARU & $\mathrm{HF}$ & & & Europe & Offshore & USA \\
\hline Broker/Dealer & 0.46 & 0.32 & 0.14 & 4.67 & 0.52 & 0.31 & 0.28 \\
\hline Commodities Brokers & 0.70 & 0.48 & 0.22 & 7.93 & 0.58 & 0.56 & 0.33 \\
\hline Investment Adviser & 0.87 & 0.67 & 0.19 & 9.30 & 0.84 & 0.76 & 0.51 \\
\hline Bank & 0.20 & 0.13 & 0.07 & 2.92 & 0.41 & 0.10 & 0.09 \\
\hline Insurance & 0.15 & 0.11 & 0.04 & 1.90 & 0.23 & 0.09 & 0.11 \\
\hline Sponsor of LLP & 0.17 & 0.14 & 0.03 & 1.20 & 0.22 & 0.16 & 0.10 \\
\hline \# External Conflicts & 2.54 & 1.85 & 0.69 & 7.13 & 2.80 & 1.98 & 1.41 \\
\hline PC External Conflicts & 0.72 & 0.33 & 0.39 & 5.75 & 1.02 & 0.37 & 0.09 \\
\hline
\end{tabular}


Panel C: Internal Conflicts of Interest

\begin{tabular}{lccccccccc} 
& \multicolumn{4}{c}{ All Funds } & & \multicolumn{3}{c}{ Hedge Fund Domicile } \\
\cline { 2 - 3 } & ARU & HF & Diff & $t$-statistic & & Europe & Offshore & USA \\
\hline BuySellYourOwn & 0.12 & 0.15 & -0.03 & -1.13 & & 0.14 & 0.13 & 0.17 \\
BuySellYourselfClients & 0.74 & 0.75 & -0.02 & -0.61 & & 0.58 & 0.72 & 0.84 \\
RecSecYouOwn & 0.54 & 0.46 & 0.07 & 2.19 & & 0.62 & 0.39 & 0.54 \\
AgencyCrossTrans & 0.10 & 0.07 & 0.03 & 1.44 & & 0.15 & 0.06 & 0.07 \\
RecUnderwriter & 0.52 & 0.52 & 0.00 & -0.04 & & 0.55 & 0.48 & 0.57 \\
RecSalesInterest & 0.31 & 0.19 & 0.13 & 4.03 & & 0.39 & 0.16 & 0.17 \\
RecBrokers & 0.39 & 0.51 & -0.12 & -3.66 & & 0.39 & 0.46 & 0.60 \\
OtherResearch & 0.89 & 0.69 & 0.20 & 9.20 & & 0.69 & 0.69 & 0.71 \\
\hline \# Internal Conflicts & 3.60 & 3.34 & 0.26 & 2.31 & & 3.50 & 3.09 & 3.66 \\
PC Internal Conflicts & 0.22 & 0.09 & 0.13 & 2.00 & & 0.29 & -0.05 & 0.23 \\
\hline
\end{tabular}

Panel D: Total Frequency of Conflicts of Interest

\begin{tabular}{llllllll}
\hline \# Conflicts & 6.41 & 5.28 & 1.13 & 5.87 & 6.51 & 5.18 & 5.16 \\
PC Conflicts & 0.65 & 0.25 & 0.40 & 5.47 & 0.85 & 0.21 & 0.16 \\
\hline
\end{tabular}




\section{Table 5: Probit Model Analysis on the Past Violations}

The dependent variable in all models is 1 if the fund has a problem (past violations), and 0 if the fund does not have a problem (past violations). 'ARUs' is an indicator variable that is set to 1 if a fund is UCITS-compliant and 0 otherwise. 'PC Misvalution' is the $1^{\text {st }}$ principal component of the Bollen-Pool (2012) 'red flags'. The conflicts of interest variables are as in Table 4. 'Heckman's $\lambda$ ' is the inverse Mills ratio that is used to correct for selection bias and is obtained from the $1^{\text {st }}$ stage selection equation which models the probability that a fund files form ADV ('Problem'-indicator) to the SEC. The Probit model includes strategy fixed effects. Standard errors are corrected for clustering at the fund-level. 'Chi.Prob' refers to the associated $p$-value.

\begin{tabular}{lcccc} 
Variable & Par.Est & Chi.Prob & Par.Est & Chi.Prob \\
\hline ARU & 0.43 & $<.001$ & -0.09 & 0.46 \\
PC Misvaluation & 0.05 & 0.04 & 0.04 & 0.24 \\
& & & & \\
BrokerDealer & & & 0.75 & $<.001$ \\
InvAdviser & & & -0.01 & 0.92 \\
Commod & & 0.22 & 0.00 \\
Bank & & -0.34 & 0.00 \\
Insur & & 0.83 & $<.001$ \\
PartSponsor & & 0.90 & $<.001$ \\
& & & & \\
BuySellYourOwn & & & 0.05 & 0.51 \\
BuySellYourselfClien & & & 0.09 & 0.18 \\
RecSecYouOwn & & & 0.30 & $<.001$ \\
AgencyCrossTrans & & & 0.31 & 0.01 \\
RecUnderwriter & & & 0.07 & 0.32 \\
RecSalesInterest & & & -0.17 & 0.02 \\
RecBrokers & & & 0.06 & 0.34 \\
OtherResearch & & & 0.18 & 0.00 \\
Heckman's $\lambda$ & 0.34 & $<.001$ & 0.30 & 0.01 \\
\hline
\end{tabular}


Table 6: Risk-adjusted Performance Differences

Panel A (Panel B) reports for the equal-weighted (value-weighted) portfolios from January 2005 through June 2013. 'Alpha' refers to the annualized intercept of the 9-factor model. ' $t$-stat' is the Newey-West (1987) adjusted $t$-statistic of alpha. Risk loadings are estimated using the excess returns of the S\&P 500 index (SP), the return spread between the Russell 2000 index and the S\&P 500 index (SIZE), the excess return of ten-year Treasuries (CGS10), the spread return between Moody's BAA and ten-year Treasuries (CREDSPR), the excess returns of look-back straddles on bonds (PTFSBD), currencies (PTFSFX), and commodities (PTFSCOM) as well as the excess return of the MSCI Emerging Market Index (MSEMKF) and the Lustig, Roussanov, and Verdelhan (2011) currency risk factor (RX). ' $R^{2}$ ' refers to the R-squared of the model. Panel C (Panel D) reports cross-sectional medians of individual funds and their differences tests for the study period from January 2005 through December 2009 (January 2010 through June 2013). Measures are computed for fund that have at least 24 return observations using Getmansky, Lo and Makarov (2004) smoothing adjusted returns. 'Mean' denotes the fund's average return. 'Std' denotes the fund's return standard deviation. 'Sharpe' denotes the annualized Sharpe ratio. 'ES' denotes historical expected shortfall at the 10\% level. 'MPPM' is the Goetzmann, Ingersoll, Spiegel and Welch's (2007) Manipulation-proof Performance Measure. 'SystRisk' is defined as the difference of return standard deviation and residual risk. 'IdioRisk' denotes the residual risk that is obtained from the 9-factor model.

Panel A: Equal-weighted Portfolios of Hedge Funds (HF) and UCITS-compliant Funds (ARU)

\begin{tabular}{lcccccccccccc} 
Class & Alpha & $t$-stat & SP & SIZE & CGS10 & CREDSPR & PTFSBD & PTFSFX & PTFSCOM & MSEMKF & RX & $R^{2}$ \\
\hline HF & 1.176 & 1.362 & 0.063 & -0.025 & -0.112 & 0.106 & 0.005 & 0.005 & -0.004 & 0.174 & 0.385 & 0.914 \\
ARU & -1.061 & -0.975 & 0.142 & -0.078 & -0.044 & 0.151 & 0.008 & 0.003 & -0.004 & 0.261 & 0.862 & 0.954 \\
\hline Difference & -2.237 & -2.337 & 0.080 & -0.052 & 0.068 & 0.045 & 0.003 & -0.002 & 0.000 & 0.087 & 0.477 & 0.040 \\
$t$-statistic & -2.38 & -2.44 & 2.65 & -1.20 & 0.97 & 1.28 & 0.31 & -0.41 & 0.01 & 4.02 & 6.11 &
\end{tabular}

Panel B: Value-weighted Portfolios of Hedge Funds (HF) and UCITS-compliant Funds (ARU)

\begin{tabular}{lcccccccccccc} 
Class & Alpha & $t$-stat & SP & SIZE & CGS10 & CREDSPR & PTFSBD & PTFSFX & PTFSCOM & MSEMKF & RX & $R^{2}$ \\
\hline HF & 1.502 & 1.412 & 0.036 & -0.082 & -0.068 & 0.098 & 0.005 & 0.000 & 0.005 & 0.160 & 0.273 & 0.814 \\
ARU & -1.057 & -0.862 & 0.092 & -0.117 & -0.078 & 0.145 & 0.013 & 0.000 & -0.004 & 0.173 & 1.087 & 0.930 \\
\hline Difference & -2.559 & -2.274 & 0.056 & -0.036 & -0.010 & 0.047 & 0.008 & -0.001 & -0.009 & 0.013 & 0.814 & 0.116 \\
$t$-statistic & -2.24 & -2.21 & 1.49 & -0.86 & -0.13 & 1.42 & 0.59 & -0.14 & -1.42 & 0.47 & 10.45 &
\end{tabular}


Panel C: Medians from January 2005 to December 2009

\begin{tabular}{lcccccc} 
& & \multicolumn{5}{c}{ A set of performance and risk measures } \\
\cline { 3 - 7 } All Funds & $\mathrm{N}$ & Mean & Std & Sharpe & ES & MPPM \\
\hline ARU & 132 & 3.07 & 23.53 & 0.15 & 12.13 & -13.66 \\
HF & 9151 & 3.13 & 16.78 & 0.20 & 8.19 & -4.75 \\
Difference & & -0.06 & 6.75 & -0.05 & 3.94 & -8.91 \\
$t$-statistic & & -0.73 & 5.35 & -0.85 & 5.92 & -5.08 \\
\hline
\end{tabular}

\begin{tabular}{ccccc}
\multicolumn{5}{c}{ 9-Factor Model } \\
\hline Alpha & $t$-stat & SystRisk & IdioRisk & $R^{2}$ \\
\hline-0.48 & -0.08 & 11.92 & 10.64 & 0.75 \\
0.65 & 0.09 & 5.28 & 10.92 & 0.40 \\
\hline-1.12 & -0.17 & 6.64 & -0.28 & 0.35 \\
-3.00 & -2.02 & 10.62 & -1.49 & 13.95 \\
\hline
\end{tabular}

Panel D: Medians from January 2010 to June 2013

\begin{tabular}{lcccccc} 
All Funds & $\mathrm{N}$ & Mean & Std & Sharpe & ES & MPPM \\
\hline ARU & 456 & 1.35 & 15.13 & 0.10 & 7.76 & -4.63 \\
HF & 8460 & 3.42 & 14.61 & 0.27 & 7.04 & -1.93 \\
\cline { 3 - 7 } Difference & & -2.07 & 0.52 & -0.17 & 0.72 & -2.70 \\
$t$-statistic & & -5.90 & 4.05 & -8.26 & 7.11 & -7.48 \\
\hline
\end{tabular}

\begin{tabular}{ccccc} 
Alpha & $t$-stat & SystRisk & IdioRisk & $R^{2}$ \\
\hline 0.36 & 0.06 & 8.93 & 5.38 & 0.80 \\
0.87 & 0.14 & 5.75 & 7.24 & 0.51 \\
\hline-0.51 & -0.08 & 3.17 & -1.86 & 0.30 \\
-3.36 & -3.94 & 14.19 & -9.94 & 19.71 \\
\hline
\end{tabular}




\section{Table 7: Multivariate Performance Regressions}

This table reports results from a regression model where the monthly fund's 9-factor alpha is regressed on 'ARU', an indicator variable that is 1 if the fund is UCITS-compliant and 0, otherwise. The other explanatory variables used are described in Table 2. 'Baseline' provides results for the base case including all funds. 'Selection Bias Correction' corrects sample selection bias using the Heckman method. The first stage of this method models the propensity that the fund is UCITS-compliant. In the second stage the fitted values of the ARU indicator are used as independent variables. The time period is from January 2005 through June 2013. Strategy and time fixed effects are included. Standard errors are corrected for within-fund clustering. 'Chi.Prob' refers to the associated $p$-value.

\begin{tabular}{|c|c|c|c|c|c|c|}
\hline & \multirow{2}{*}{\multicolumn{2}{|c|}{ Baseline }} & \multicolumn{4}{|c|}{ Selection Bias Correction } \\
\hline & & & \multicolumn{2}{|c|}{ 1st stage } & \multicolumn{2}{|c|}{ 2nd stage } \\
\hline & Par.Est. & t-stat & Par.Est. & Chi.Prob & Par.Est. & t-stat \\
\hline ARU & -0.0012 & -4.29 & & & -0.0002 & -2.45 \\
\hline $\log (1+$ Restriction $)$ & 0.0013 & 2.61 & & & 0.0018 & 3.27 \\
\hline Leverage & 0.0004 & 2.71 & & & 0.0003 & 1.58 \\
\hline $\log (1+$ Min. Invest. $)$ & 0.0006 & 4.02 & & & 0.0005 & 3.37 \\
\hline $\log (1+\operatorname{Lockup})$ & 0.0006 & 2.14 & & & 0.0004 & 1.40 \\
\hline Management Fee & 0.0033 & 0.22 & -34.65 & $<.001$ & & \\
\hline Incentive Fee & 0.0037 & 2.34 & -3.29 & $<.001$ & 0.0034 & 1.83 \\
\hline High-Water Mark & 0.0009 & 4.01 & & & 0.0008 & 3.13 \\
\hline Lagged Size & 0.0001 & 1.54 & & & 0.0001 & 2.17 \\
\hline Lagged Age & -0.0001 & -3.72 & & & -0.0001 & -4.04 \\
\hline Lagged Flow & 0.0009 & 1.72 & & & 0.0006 & 1.03 \\
\hline Inception Family Size & & & 0.09 & $<.001$ & & \\
\hline
\end{tabular}




\section{Table 8: Liquidity-Performance Trade-off}

Panel A (Panel C) reports the annualized alpha differences between ARUs and liquid (illiquid) European onshore hedge funds. Panel B reports the liquidity-Performance trade-off for European onshore hedge funds and ARUs. 'Restriction' is the sum of redemption period and notice period in days. '9-Factor Model' is defined in the previous table. '11-Factor Model' includes the additional factors. 'BaB' is the factor loading for the Betting-Against-Beta factor (Frazzini and Pedersen 2014). 'PS' is the factor loading for the market liquidity risk (Pastor and Stambaugh 2003).

Panel A: ARUs vs. Liquid European Onshore Funds

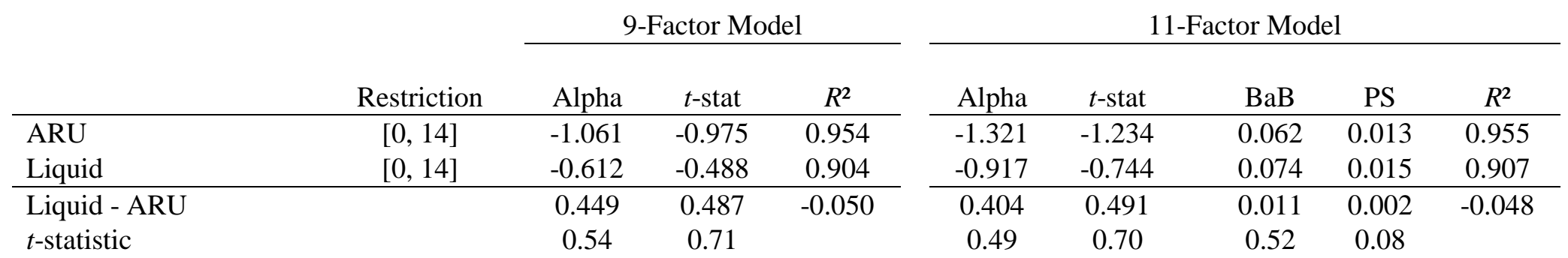

Panel B: European Onshore Funds Liquidity Performance Trade-off

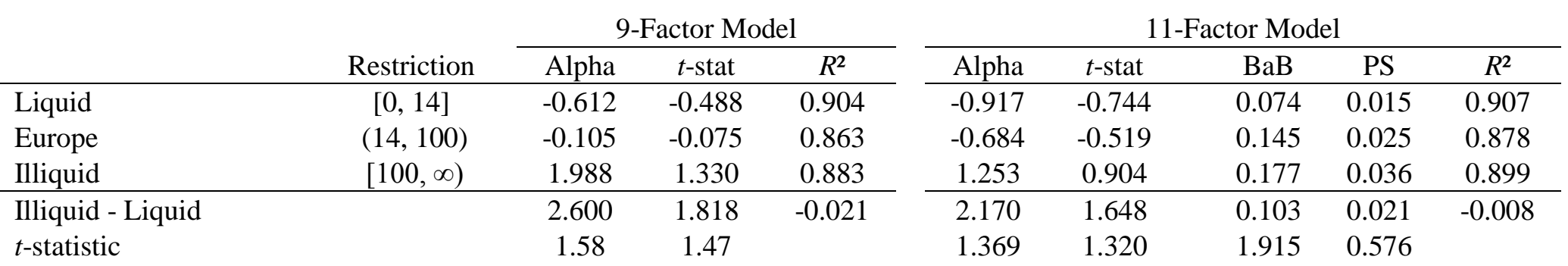

Panel C: ARUs vs. Illiquid European Onshore Funds

\begin{tabular}{|c|c|c|c|c|c|c|c|c|c|}
\hline & \multirow[b]{2}{*}{ Restriction } & \multicolumn{3}{|c|}{ 9-Factor Model } & \multicolumn{5}{|c|}{ 11-Factor Model } \\
\hline & & Alpha & $t$-stat & $R^{2}$ & Alpha & $t$-stat & $\mathrm{BaB}$ & PS & $R^{2}$ \\
\hline ARU & {$[0,14]$} & -1.061 & -0.975 & 0.954 & -1.321 & -1.234 & 0.062 & 0.013 & 0.955 \\
\hline Illquid & {$[100, \infty)$} & 1.988 & 1.330 & 0.883 & 1.253 & 0.904 & 0.177 & 0.036 & 0.899 \\
\hline Illquid - ARU & & 3.049 & 2.305 & -0.071 & 2.574 & 2.139 & 0.115 & 0.023 & -0.056 \\
\hline$t$-statistic & & 1.97 & 1.92 & & 1.76 & 1.77 & 2.56 & 0.82 & \\
\hline
\end{tabular}




\section{Table 9: Comparing Matched UCITS and non-UCITS funds}

Panel A (Panel B) presents the pooled regression results for the matched UCITS and non-UCITS funds that belong to the same management firm (are managed by the same fund manager side-by side). ' $\Delta$ FH9 Alpha' refers to 9-factor alpha difference of the UCITS-compliant and non-UCITS. ' $\triangle F H 11$ Alpha' refers to respective 11 -factor alpha difference. 'Restriction dummy' gets a value of 0 if both of the funds in a pair provide at least biweekly liquidity and 1 if the hedge fund's restriction period is longer than two weeks. 'ALeverage' is the difference in average leverage of UCITS and non-UCITS fund. The $\Delta$ Control variables are constructed as in Table 7, but we take differences. We control for both strategy and time fixed effects. Standard errors are adjusted for within fund cluster correlation.

Panel A: Only UCITS and non-UCITS Pairs from to the Same Management Company

\begin{tabular}{lccccc} 
& \multicolumn{2}{c}{$\Delta$ FH9 Alpha: HF - ARU } & & \multicolumn{2}{c}{$\Delta$ FH11 Alpha: HF - ARU } \\
\cline { 2 - 3 } \cline { 5 - 6 } & Par.Est. & t-stat & & Par.Est. & t-stat \\
\hline Restriction dummy & 0.0015 & 1.92 & & 0.0018 & 2.06 \\
SLeverage & 0.0017 & 4.26 & & 0.0015 & 2.71 \\
Control variables? & Yes & & & Yes & \\
Strategy and time & Yes & & & Yes & \\
effects? & & & & & \\
\hline
\end{tabular}

Panel B: Only UCITS and non-UCITS Pairs with the Same Fund Manager (Side-by-Side Management)

\begin{tabular}{lccccc} 
& \multicolumn{2}{c}{$\Delta$ FH9 Alpha: HF - ARU } & & \multicolumn{2}{c}{$\Delta$ FH11 Alpha: HF - ARU } \\
\cline { 2 - 3 } \cline { 5 - 6 } & Par.Est. & t-stat & & Par.Est. & t-stat \\
\hline Restriction dummy & 0.0085 & 5.07 & & 0.0125 & 5.11 \\
LLeverage & 0.0072 & 5.30 & & 0.0075 & 4.24 \\
Control variables? & Yes & & & Yes & \\
Strategy and time & Yes & & & Yes \\
effects? & & & & & \\
\hline
\end{tabular}




\section{Online Appendix: Effect of Regulatory Constraints on Fund Performance: New Evidence from UCITS Hedge Funds}

Table of Contents:

Appendix A: UCITS Regulation

Appendix A.1: Evolution of UCITS Regulation

Appendix A.2: Current UCITS (IV) Regulation Requirements

Appendix B: Robustness Tests:

B.1. Data Gathering Process

B.2. Operational Risk

B.2.1. Suspicious Patterns in Reported Returns

B.2.2 Conflicts of Interest

B.2.2. Heckman Correction for w-score and in Probit Model Analysis

B.3. Risk-adjusted Returns

B.3.1. Baseline Results

B.3.2. Local-Currency Excess Returns

B.3.3 Fung-Hsieh Risk-Adjusted Returns

B.3.4. Stepwise Risk-Adjusted Returns

B.3.4. Liquidity Sorts

B.4. Performance Persistence 


\section{Appendix A: UCITS Regulation}

UCITS (Undertakings for Collective Investment in Transferable Securities) refers to a set of European Union Directives establishing a harmonized legal framework for the creation, management and marketing of collective investment schemes in the EU (and EEA) Member States. Below we briefly review how UCITS fund rules have evolved over time and summarize the requirements under the latest version of UCITS that is UCITS IV.

\section{Appendix A.1: Evolution of UCITS Regulation}

\section{UCITS I (1985)}

The aim of the original UCITS Directive 85/611/EEC, adopted in 1985, was to allow for openended funds investing in transferable securities to be subject to the same regulation in every Member State. Under UCITS I, derivatives could only be used for hedging and efficient portfolio management, that is with the aim of reducing risk or cost, or to replicate a position that could otherwise be achieved through investing in the underlying asset.

\section{UCTIS II (early 1990s)}

In the early 1990s attempts were made to amend the 1985 Directive and more successfully harmonize laws throughout Europe, since several obstacles become apparent in following UCITS I. Individual marketing rules in each Member State created obstacles to cross-border marketing of UCITS. The limited definition of permitted investments for UCITS also weakened the marketing possibilities of a UCITS. Attempts to reform UCITS in the 1990s faltered and it was not until the introduction in 2001 of Directive 2001/108/EC (generally known as the "Product Directive") and Directive 2001/107/EC (generally known as the "Management Directive") that substantive change was eventually introduced. ${ }^{1}$

UCITS III (2002):

The UCITS III revision gave asset managers a broader scope of eligible assets. At the same time, the requirements on investor protection were increased and called for an independent risk

\footnotetext{
${ }^{1}$ The Product Directive and the Management Directive are generally collectively referred to as "UCITS III".
} 
management function (to limit/monitor leverage, counterparty risk, concentration limits, etc.). UCITS III expanded the range of available investments to include derivatives for investment purposes, other UCITS and cash. This dramatically increased investor choice, allowing for cash funds, funds of fund, mixed asset funds and absolute return UCITS or UCITS hedge funds. This has allowed a number of hedge fund strategies to be accommodated within the UCITS format such as equity long/short, relative value, etc. Some strategies, however, remain difficult to implement within the UCITS framework because the underlying asset class is not permissible (for example, individual commodities or bank loans) or because of the lack of liquidity (for example, distressed debt).

\section{UCITS IV (2009-11)}

The UCITS IV directive introduced the management company passport and allows a UCITS to be managed by a management company authorised and supervised in a Member State other than its home Member State. UCITS IV has increased the governance ("organisational") requirements of UCITS Management Companies and funds and has brought these requirements more in line with MIFID. ${ }^{2}$ UCITS or its management company needs to establish independent compliance and audit functions in addition to the independent risk management which was already required under UCITS III but which has been expanded to formalise the management of a variety of risks.

The "organization directive" contains requirements for organizational and internal control, and conflicts of interest. According to the directive conflicts of interest may arise if:

- the management company is likely to make a financial gain, or avoid a financial loss, at the expense of the UCITS fund;

- the management company has an interest in the outcome of a service provided to the UCITS or another client which does not share the interests of the UCITS fund;

- the management company has an incentive to favour the interest of another client;

- the management company carries out the same activities for the UCITS as for another client;

- the management company receives money, goods or services illegally.

\footnotetext{
${ }^{2}$ The Markets in Financial Instruments Directive 2004/39/EC (known as "MiFID") is a European Union law that aims at creating harmonized regulation for investment services across the 30 member states of the European Economic Area (the 27 Member States of the European Union plus Iceland, Norway and Liechtenstein). See, for example, http://ec.europa.eu/internal_market/securities/isd/index_en.htm\#isd.
} 
UCITS V (2013-2015)

The UCITS V directive was adopted by the European Union on 23 July 2014. There are three key elements in the directive which govern (1) depositaries' duties, (2) remuneration policies including retention and deferral of variable remuneration and (3) a sanctions regime. The remuneration policies are required to (i) be consistent with and promote sound and effective risk management of the UCITS, (ii) should not encourage risk-taking which is inconsistent with the risk profiles or fund rules governing the relevant UCITS and (iii) not impair compliance with the UCITS Manager's duty to act in the best interest of the UCITS. UCITS V can be compared with the Alternative Investment Fund Managers Directive ("AIFMD"), which is a parallel regulation for hedge funds and alternative investments.

UCITS VI (Consultation Period)

A consultation document for the UCITS VI directive has been issued. The EU commission asks respondents whether there is a need to review the list of eligible assets under UCITS. Other topics in the consultation paper include efficient portfolio management, OTC derivatives, liquidity management and money market funds.

\section{Appendix A.2: Current UCITS (IV) Regulation Requirements}

\section{A.2.1 Eligible Assets:}

A UCITS can only invest in eligible assets. The eligible assets that a UCITS can invest in include:

- Transferable securities - essentially, publicly traded equities or bonds, listed on mainstream stock exchanges.

- Deposits and Money Market instruments (MMIs) - Cash deposits with "credit institutions" (i.e. banks) can be held as investment assets, together with MMIs. These might include treasury and local authority bills, certificates of deposit or commercial paper. Thus pure cash funds can be UCITS.

- Certain other funds: open-ended mutual funds where those are other UCITS or non-UCITS funds with UCITS-like traits. This has allowed the development of UCITS funds of funds.

- Financial Derivative Instruments (following UCITS III): funds are able to use derivatives for investment purposes, using exchange-traded or over-the-counter (“OTC") instruments, with some limitations. The underlying of a derivative must be one of the following types (i) an eligible asset of the type mentioned above, (ii) interest rates, (iii) currencies, (iv) financial 
indices.

- Short-selling: Physical short selling is not permitted. However, the same economic effect can be achieved and is allowed through the use of derivatives such as Contracts for Difference (“CFDs").

- Ineligible assets - certain assets remains out of scope:

- Real estate

○ Bank loans

○ Physical metals such as gold (although certain securities based on metals are permitted)

○ Commodities (although derivatives on financial indices such as commodity indices are eligible)

\section{A.2.2. Diversification Requirements, Risk and Leverage Limits:}

Diversification rules:

UCITS must operate on a principle of risk spreading, which means that restrictions apply which limit the spread of investments, leverage and exposure. A UCITS must be properly diversified. The socalled 5/10/40 Rule states that a UCITS cannot invest more than 5\% of its assets in securities issued by a single issuer. However, this limit can be increased up to $10 \%$ provided that where the $5 \%$ limit is exceeded, the exposure to these issuers, when added together, does not exceed $40 \%$ of the fund's assets. There are also rules around the proportion of a company that a UCITS may hold in that it might gain significant influence over its management. Rules exist too regarding the amount of a company's debt or non-voting shares that can be held.

Risk Limits:

There are two approaches to risk limits: the commitment approach and the VaR (Value-at-Risk) approach.

\section{The Commitment Approach}

This essentially aggregates the underlying notional value of stock and derivatives to determine the degree of gross exposure (called "global exposure" in the Directive). The commitment approach is potentially suitable for Long-only funds, or UCITS funds making a simple or limited use of 
derivatives. Under the commitment measure, the leverage limit generated by using financial derivatives is limited to $100 \%$ of the UCITS' net asset value. With the $10 \%$ short term overdraft facility that all funds are permitted, this means the total gross exposure of the fund cannot exceed $210 \%$ of the net asset value of the fund.

\section{Value at Risk}

The VaR approach is an alternative to the commitment approach and has two versions, the absolute and the relative $\mathrm{VaR}$ approach. The $\mathrm{VaR}$ approach has advantages over the commitment approach since it captures risk exposures better and is more suitable for funds that make use of derivatives. Gross exposures can be quite high in funds that use derivatives or shorting. The VaR limit, for UCITS purposes, is calculated on a monthly basis using a confidence interval of 99\%. The VaR can be either calculated in absolute or in relative terms. Absolute return UCITS must limit their 1-month 99\% VaR to twice that of the benchmark index. Absolute return funds must stand within the limit of $20 \%$.

\section{A.2.3. Liquidity requirements and custody:}

A UCITS must be open-ended i.e. shares or units in the fund may be redeemed on demand by investors. A UCITS must be liquid, that is, its underlying investments must be liquid enough to support redemptions in the fund on at least a fortnightly basis. In practice, most UCITS funds UCITS funds allow daily dealing. Assets must be entrusted to an independent custodian or depositary and held in a ring-fenced account on behalf of investors. 


\section{Appendix B: Robustness Tests}

\section{B.1. Data Gathering Process}

Our data comes mainly from a consolidation of five commercial hedge fund database (Barclay Hedge, Eureka Hedge, Hedge Fund Research, Morningstar, and Lipper TASS). Lipper TASS includes virtually no ARU funds ${ }^{3}$, and rest of the databases include indicators of whether the fund is UCITS compliant. We use these indicators to classify the funds into absolute return UCITS funds (ARU) and hedge funds (HF). Furthermore, to study the effects of geography and regulation more carefully, we decompose hedge funds (HF) further into European onshore (Europe), global offshore (Offshore) and US-based (USA) hedge funds. Our raw sample period is from January 2003 to June 2013, since the first UCITScompliant alternative funds started appearing in 2003. But in our empirical tests we use the sample period from January 2005 to June 2013, to mitigate the problems associated with survivorship bias (Table 1 of main paper).

It is not a trivial task to merge several commercial hedge fund databases and to identify unique hedge funds based on information on multiple share classes. The main reason is that commercial data vendors only provide an identifier for unique share classes, but they do not provide identifiers for distinct hedge funds. We use the Joenväärä, Kosowski, and Tolonen (2014) merging approach, to identify unique hedge funds. However, we hand-match ARUs as clusters that have a unique root fund name. The rationale is a large number of currency share classes that are difficult to match using a statistical merging approach. Table B1 reports the number of unique ARUs we have in our database. There is significant number of currency share classes. Even though there are a large number UCITScompliant funds that are denominated in euros, we convert (using rates from Bloomberg) both UCITS and non-UICTS funds' returns and AuMs into US dollars because the majority of hedge funds report their returns in US dollars.

\section{B.2. Operational Risk}

\section{B.2.1. Suspicious Patterns in Reported Returns}

To investigate whether funds misreport their returns, we use a set of measures proposed by Bollen and Pool (2012). Following their paper, we require at least 24 months of contiguous returns. Untypical to hedge fund studies, the returns are not backfill-adjusted, since we are interested in suspicious patterns

\footnotetext{
${ }^{3}$ We hand-collect few UCITS compliant funds from Lipper TASS and reclassify them as UCITS funds.
} 
everywhere in the return series. Bollen and Pool use returns only from US dollar denominated funds, but our data includes non-US funds (most ARUs are euro denominated), so we have modified their measures by specifying for each measure whether it is more naturally calculated using USD-converted returns, or non-currency-converted returns. The original measures of Bollen and Pool are indicator variables that take a value of one if a measure-specific null hypothesis is rejected at $10 \%$ level. For simplicity, though, we have mostly used the test statistics instead of the resulting indicators, since finding the critical values is complicated. However, significant differences in the test statistics should reflect significant differences in the indicator variables. ${ }^{4}$

- The only asset liquidity measure we have replicated here is the Autocorrelation, which refers to the test statistic of the first-order coefficient in a MA(1) -model of non-currency-converted returns, with higher values associated with more manipulation.

- The proxy for discontinuity in the distribution of non-currency-converted returns around zero, or the so-called Kink measure. It refers to the test statistic measuring whether small losses are reported at a suspiciously low rate compared to small gains. Smaller values are associated with higher return manipulation.

- Two measures of low correlation: Index $R^{2}$ is the $p$-value of the slope coefficient from a regression of USD-converted fund returns on a corresponding equally-weighted style index, with higher values denoting more return manipulation. $\operatorname{Max} R^{2}$ is the maximum adjusted Rsquare of fund USD-converted returns against the seven factors of Fung and Hsieh (2004) and the four option factors of Agarwal and Naik (2004), with lower values denoting more return manipulation; the optimal factors maximizing the adjusted $R$-square are found via stepwise regression, with a maximum number of factors of six.

- Four measures of data-quality, all based on non-currency-converted returns. The calculation of these measures is sometimes simplified from the original measures of Bollen and Pool (2012). Measure \% Repeat refers to an indicator that takes a value of one if the fund has a repeat of at least three returns (rounded to four decimals), with higher values corresponding to more return manipulation. Measure \# Zero is the number of zero returns, with larger values corresponding to more return manipulations, Measure \% Negative refers to the fraction of negative returns corresponding to more return manipulation. Measure Uniform refers to the test statistic of the uniformity of the last digit in reported returns again corresponding to more return manipulation.

\footnotetext{
${ }^{4}$ Bollen and Pool themselves also use the non-indicator versions in some of their regressions.
} 
In Table B2, we report suspicious patterns in reported returns only for hedge funds that are domiciles in Europe. We still find that European onshore hedge funds report more suspicious return patterns compared to UCITS-compliant funds. We can therefore conclude that our results are not driven by geography or domicile effects.

\section{B.2.2 Conflicts of Interest}

The Securities and Exchange Commission (SEC) requires US-based professional investment advisors (exceeding a threshold on assets under management and number of clients) to register as such by filing an annually updated Form ADV report, which includes rich information about, for example, the advisor's assets, clients, employees, investment style, affiliates, and history. The Item 11 of the Form ADV asks for past legal or regulatory violations of the advisor or its affiliates, and Brown et al. (2008, 2009) show that these past violations are connected to other information in the Form ADVs, such as conflicts of interest, and also to hedge fund characteristics.

We use the historical filings available at Historical Archive of Investment Adviser Reports (http://www.sec.gov/foia/iareports/inva-archive.htm). These filings contain only the basic items of the Form ADV report, and not the additional schedules, which are also used by Brown et al. (2008, 2009) to gather information about managerial ownership. We use the snapshot of Form ADV reports of June 2013, and use only Item 7 (external conflicts of interest), Item 8 (internal conflicts of interest), and Item 11 (past violations). From these items, we extract advisor-level indicator variables, which are then mapped to fund-level. From Item 7, we extract six indicators of external conflicts of interest, namely relations to broker-dealers (RelBrokerDealer), commodities brokers (RelCommod), investment advisors (RelInvAdviser), banks (RelBank), insurance companies (RelInsur), and sponsorship to limited partnerships (RelPartSponsor). From Item 8, we extract eight indicators of internal conflicts of interest: whether the advisor buys and sells securities between itself and its clients (BuySellYourOwn); whether the advisor recommends securities in which a related party has an ownership interest (RecSecYouOwn); whether the advisor performs agency cross transactions (AgencyCrossTrans); whether a related party recommends securities to clients for which they are the underwriter (RecUnderwriter); whether a related party recommends securities with a sales interest (RecSalesInterest); and whether the advisor uses external research (OtherResearch). From Item 11 I extract a single problem indicator (Problem) that takes a value of one if the advisor (or any of its related persons) has had legal or regulatory 
violations during the last 10 years. Finally, we have calculated a sum of external indicators (SumExternal), a sum of internal indicators (SumInternal) and a sum of all indicators (SumTotal). We also have calculated the first principal components for all of these.

\section{B.2.2. Omega-score and Probit Model Analysis}

To estimate Omega-scores $(\omega)$ for each fund, we use its advisor's Form ADV from June 2013 to find the fund's Problem indicator variable. Omega is defined as the fitted value from a probit model of the Problem indicator against a number of fund characteristics. ${ }^{5}$ In other words, $\omega$ predicts the Problem indicator, but is applicable to all funds, not just those registered with SEC. The estimation has been done using all hedge funds, or only those with European domicile.

More precisely, we first run a probit model for an ADV indicator (equal to whether the fund's advisor has a Form ADV report as of June 2013) against 10 fund variables known through previous research to be related to operational risk: six static variables (Management Fee, Incentive Fee, Highwater Mark, Notice Period, Lockup Dummy, Leverage Dummy) and four dynamic (based on a 12month rolling window) variables (Average Return, Standard Deviation, Auto Correlation, Log of AuM, Age). The inverse Mills ratio of the fitted probability from this probit model constitutes the fund's $\lambda$ measure, which is a proxy for the fund's propensity for filing Form ADV.

Table B3 shows the results of these probit regressions. For robustness, we have estimated the models separately for all funds (Global) and European funds only (Europe), although the only global version is used later. The coefficient for fund size is also consistently positive, consistent with a size threshold required for SEC registration.

\section{B.3. Risk-adjusted Returns}

This section discusses the assumptions that are used in our fund performance analysis. Backfill- and size-adjustment is done simultaneously, by removing all observations that are either among the first 12 return observations, or are observed before first hitting the minimum AUM of $\$ 5$ million.

\section{B.3.1. Baseline Results}

The baseline results presented in main paper are estimated using the following steps. These excess return statistics are calculated using Getmansky, Lo, and Makarov (2004) (hereafter GLM) unsmoothed

\footnotetext{
${ }^{5}$ The other possible Omega's definition would be the canonical correlation of fund characteristics against Form ADV variables.
} 
USD returns. Returns used are backfill- and size-adjusted. Mean, Std, Sharpe and MPPM are in annualized percentage. $M P P M$ is calculated with risk aversion coefficient of 5 . ES is in monthly percentage and calculated at $90 \%$ level. MaxDrawdown is in percentage. Untabulated results suggest that conclusions are unchanged if we use maximum drawdown instead of ES.

\section{B.3.2. Local-Currency Excess Returns}

These excess return statistics are the same as in previous subsection, but the returns used are in local currencies. We find that our results are not sensitive to the currency choice or transformation. Among other things, this reduces the volatility of euro funds, since EUR-to-USD conversion increases return volatility. Left-hand side of Panel A of Table B4 shows that our baseline performance results holds when we use local currencies instead of USD-transformed currencies.

\section{B.3.3 Fung-Hsieh Risk-Adjusted Returns}

These risk-adjusted return statistics are calculated using GLM-unsmoothed USD returns. Returns used are backfill- and size-adjusted. The risk factors used are the FH9 factors. Alpha, SystRisk and IdioRisk are in annualized percentage. Alpha $t$-statistic is period-independent. $R^{2}$ is the adjusted R-square.

\section{B.3.4. Stepwise Risk-Adjusted Returns}

These risk-adjusted return statistics are the same as in previous subsection, but calculated using stepwise regression against a large set of 26 risk factors. The factors used are the nine (FH9) factors, four US Carhart factors, four Global Carhart factors, four European Carhart factors, two Agarwal-Naik option factors (Call_OTM and Put_OTM), and three additional factors (BaB, QMJ, PS). BaB is the betting-against-beta -factor proposed by Frazzini and Pederssen (2014). QMJ is the quality-minus-Junk -factor proposed by Asness, Frazzini and Pederssen (2013). PS is the Pastor and Stambaugh (2003) Liquidity risk -factor.

Right-hand size of Panel A of Table B4 shows that our results holds even after taking into account a large set of risk-factors. Hence, we believe that the omitted risk factors do not drive our results.

Panel B of Table B4 shows that our results are consistent across investment objectives. This finding suggests that performance differences between ARUs and HFs are not specific to those objectives and so points to more fundamental differences between the two groups. The HFs and ARUs 
that employ a Long Only strategy exhibit an interesting convergence in terms of risk and performance. Perhaps that is because, in this investment style, impediments to implementation of hedge fund-like strategies are less significant owing to the lower probability of hedge funds in this group using derivatives and other dynamic trading strategies

\section{B.4. Performance Persistence}

For performance persistence testing, we conduct sorts on 24-month alpha $t$-statistics. The baseline Figures 3 and 4 presented in paper provide results when the portfolio is rebalanced at "monthly", "bimonthly", "quarterly", "triannual", "semiannual" and "annual" horizons, corresponding to a rebalancing frequency of $1,2,3,4,6$ and 12 months, respectively. ${ }^{6}$

Tables B5 and B6 report a large set of performance and risk measures for monthly and annual

sorts. ${ }^{7}$ Bootstrapped spread and monotonicity tests are based on 5,000 Politis-Romano block bootstrap replications with an expected block length of six months. The replications are generated from the sorted portfolios using the same sample dates for each portfolio, and thus preserve the dependency structure between the portfolios. We find that the conclusion is robust across a wide range of performance measures.

\section{References}

Agarwal, V., and Naik, N.Y., 2004. Risks and Portfolio Decisions Involving Hedge Funds, Review of Financial Studies, 17(1), 63-98.

Asness C., Frazzini A., and Pedersen L.H., 2013. Quality minus junk. Working paper.

Banegas, A., Gillen, B., Timmermann, A. and Wermers, R., 2013. The cross section of conditional mutual fund performance in European stock markets. Journal of Financial Economics 108(3), 699-726.

Bollen, N. P., and Pool, V. K., 2008. Conditional return smoothing in the hedge fund industry, Journal of Financial and Quantitative Analysis 43, 267-298.

\footnotetext{
${ }^{6}$ Notice that the first portfolios are always formed on December 2004, so that the sorted portfolio returns range over the whole period January 2005 to June 2013.

${ }^{7}$ All sorts are based on USD returns of backfill- and size-adjusted funds.
} 
Bollen, N.P., Pool, V.K., 2009. Do hedge fund managers misreport returns? Evidence from the pooled distribution, Journal of Finance 64, 2257-2288.

Bollen, N.P., and V.K. Pool. 2012. Suspicious patterns in hedge fund returns and the risk of fraud. Review of Financial Studies 25, 2673-2702.

Brown S., W. Goetzmann, B. Liang, and C. Schwarz, 2008. Mandatory Disclosure and Operational Risk: Evidence from Hedge Fund Registration, Journal of Finance, 63(6), pp. 2785- 2815.

Brown S., W. Goetzmann, B. Liang, and C. Schwarz, 2009. Estimating Operational Risk for Hedge Funds: The $\Omega$-Score, Financial Analysts Journal, 65(1), pp. 43-53.

Carhart, M (1997), On persistence in mutual fund performance. Journal of Finance, 52, 57-82.

Frazzini A. and L.H. Pedersen (2014), Betting Against Beta, Journal of Financial Economics, 111, 125 .

Fung, W., Hsieh, D., 2000. Performance characteristics of hedge funds and CTA funds: Natural versus spurious biases. Journal of Financial and Quantitative Analysis 35, 291-307.

Fung, W., Hsieh, D., 2004. Hedge fund benchmarks: a risk based approach. Financial Analyst Journal $60,65-80$.

Fung, W. and Hsieh D., 2009, Measurement biases in hedge fund performance data: An update, Financial Analysts Journal 65, 36-38.

Getmansky, M., Lo A., and Makarov I., 2004. An econometric model of serial correlation and illiquidity of hedge fund returns. Journal of Financial Economics. 74, 529-610.

Goetzmann W., Ingersoll J., Spiegel M., and Welch I., 2007. Portfolio performance manipulation and manipulation-proof performance measures. Review of Financial Studies 20 (5), 1503-1546.

Heckman J.J, 1987. Sample selection bias as a specification error. Econometrica, 153-161.

Joenväärä, J., Kosowski, R., and Tolonen, P., 2014. Hedge fund performance: What do we know? Imperial College Business School.

Lustig, H., N. Roussanov and A. Verdelhan. (2011). Common Risk Factors in Currency Markets. Review of Financial Studies. 24 (11), 3731-3777.

Nohel, T., Wang, Z., Zheng, L. 2010. Side-by-side management of hedge funds and mutual funds. Review of Financial Studies, 23: 2342-2373

Pastor, L. and R. F. Stambaugh (2003). Liquidity risk and expected stock returns. Journal of Political Economy 111 (3), 642-685. 


\section{Table B1: Universe of UCITS-compliant funds}

This table reports the number of unique UCITS-share classes our aggregate database contains from January 2003 to June 2013. 'Raw sample' is the number of unique funds. ' 12 returns observations' is the number of funds after requiring 12 return observations. 'Size-and backfill adjustment' is the number of funds after we have done simultaneously, by removing all observations that are either among the first 12 return observations, or are observed before first hitting the minimum AUM of $\$ 5$ million.

\begin{tabular}{cccc} 
& Raw sample & 12 return observations & Size-and backfill adjustments \\
\hline AUD & 1 & 1 & 0 \\
CHF & 9 & 7 & 5 \\
EUR & 808 & 524 & 296 \\
GBP & 173 & 119 & 70 \\
JPY & 9 & 9 & 3 \\
NOK & 15 & 7 & 3 \\
SEK & 8 & 8 & 6 \\
USD & 349 & 195 & 103 \\
\hline & 1372 & 870 & 486
\end{tabular}




\section{Table B2: Suspicious Patterns in Reported Returns in Europe}

This table compares suspicious patterns in reported returns of absolute return UCITS (ARU) and hedge funds (HF) domiciled in Europe. We require that each fund has at least 24 return observations over the period from January 2005 to June 2013. A set of used measures is based on Bollen and Pool (2012). Greater manipulation in reported returns are indicated by + or - sigs. Table reports the cross-sectional means and their difference tests. 'Autocorrelation' refers to the test statistic of the first-order coefficient in a MA(1) model of returns. 'Kink' refers to the test statistic of the kink flag, measuring the abnormal rate of reporting small losses. 'Index $\mathrm{R}^{2}$ ' is the $p$-value of the slope coefficient from a regression of fund returns on a corresponding style index. 'Max $\mathrm{R}^{2}$ ' refers to the adjusted R-square of fund returns against the seven Fung-Hsieh factors and the four Agarwal-Naik factors. '\% Repeat' is triggered by a high number of returns that are repeated. '\# Zero' refers to the number of zero returns. '\% Negative' refers to the fraction of negative returns. 'Uniform' refers to the test statistic of the uniformity of the last digit in reported returns. 'PC Misvalution' is the 1st principal component of the BollenPool (2012) 'red flags'.

\begin{tabular}{lccccc} 
'Red Flag' & Manipulation & ARU & European HFs & Diff & Stat \\
\hline$N$ & & 870 & 3496 & & \\
Autocorrelation & + & 0.10 & 0.11 & -0.01 & -1.56 \\
Kink & - & 0.11 & -0.12 & 0.23 & 4.97 \\
& & & & & \\
Index $R$ & + & 0.02 & 0.06 & -0.04 & -9.26 \\
Max $R^{2}$ & - & 0.57 & 0.45 & 0.11 & 15.77 \\
& & & & & \\
\% Repeat & + & 0.01 & 0.03 & -0.03 & -5.68 \\
\# Zero & + & 0.27 & 0.56 & -0.29 & -4.98 \\
\% Negative & - & 0.42 & 0.4 & 0.02 & 4.33 \\
Uniform & + & 15.79 & 16.23 & -0.44 & -1.38 \\
& & & & & \\
PC Misvaluation & + & -0.30 & -0.04 & -0.26 & -7.85 \\
\hline
\end{tabular}




\section{Table B3: Determinants of $\omega$-score}

This table shows the results from the probit regressions of the $\omega$-score both for 'All funds' and for European funds only (Europe). The dependent variable in the $\omega$ regressions is the Problem indicator based on the Item 11 of Form ADV on June 2013. The explanatory variables are the fund's management fee (ManagementFee), incentive fee (IncentiveFee), high-water mark dummy (HighwaterMark), notice period (Notice), lockup dummy (LockupDummy), leverage dummy (LeverageDummy), rolling mean return (AvgReturn), rolling volatility (StdDev), rolling autocorrelation (AutoCorr), rolling maximum logarithmic fund's AUM (Log_AUM), and rolling fund's age (Age), Rolling variables are based on a 12-month window. Significance is shown by $+(\mathrm{p}<$ $0.10), *(\mathrm{p}<0.05)$ and $* *(\mathrm{p}<0.01)$.

\begin{tabular}{lll} 
& \multicolumn{2}{c}{$\omega$-score } \\
\cline { 2 - 3 } Variable & All funds & Europe \\
\hline Intercept & $-0.99 * *$ & $-0.60 *$ \\
AvgReturn & $-13.94 * *$ & $-43.43 * *$ \\
StdDev & -0.63 & $-5.72 * *$ \\
AutoCorr & $-0.18+$ & 0.03 \\
Log(AUM) & $0.12 * *$ & $0.11 * *$ \\
Age & $-0.02 * *$ & -0.02 \\
Management Fee & -5.94 & 5.08 \\
Incentive Fee & $1.11 * *$ & 1.45 \\
High-Water Mark & $-0.03 * *$ & -0.08 \\
Notice period & $-0.99 * *$ & $-1.95+$ \\
Lockup Dummy & $-0.13 * *$ & $0.84 *$ \\
Leverage Dummy & $0.09 *$ & $0.22+$ \\
\hline
\end{tabular}




\section{Table B4: Risk-adjusted Performance and Risk}

Left-hand side of Panel A presents results using local currencies (without any currency transformation), while right hand-side of panel A presents results using the step-wise regression containing 26 factors described in Appendix B. Panel B presents risk-adjusted performance and risk measures for Absolute Return UCITS (ARU) and hedge funds (HF) across investment. Measures are computed for fund that have at least 24 return observations. Mean denotes the fund's average return. Std denotes the fund's return standard deviation. Sharpe denotes the annualized Sharpe ratio. ES denotes historical expected shortfall at the 10\% level. MPPM is the, Ingersoll, Goetzmann, Spiegel and Welch's (2007) Manipulation-proof Performance Measure. Alpha is the annualized 9-factor Fung and Hsieh (2004) alpha within a specific category. t-stat presents the t-statistic of FH alpha. SystRisk is defined as the difference of return standard deviation and residual risk. IdioRisk denotes the residual risk that is obtained from the 9 -factor model. $\mathrm{R}^{2}$ is the adjusted R-squared of the 9 -factor model.

Panel A: Local Currencies and Stepwise Regression

\begin{tabular}{lcccccc} 
& & \multicolumn{5}{c}{ Local Currencies } \\
\hline ARU & $\mathrm{N}$ & Mean & Std & Sharpe & ES & MPPM \\
HF & 456 & 2.14 & 9.93 & 4.92 & 0.27 & -0.33 \\
Diff & 8458 & 4.22 & 10.88 & 4.93 & 0.42 & 0.91 \\
\cline { 2 - 7 } Stat & & -2.08 & -0.95 & -0.02 & -0.15 & -1.24 \\
\hline
\end{tabular}

\begin{tabular}{ccccc}
\multicolumn{5}{c}{ Step-wise Regression with 25 factors } \\
\hline Alpha & $t$-stat & SystRisk & IdioRisk & $R^{2}$ \\
\hline-0.77 & -0.25 & 9.98 & 4.53 & 0.89 \\
1.09 & 0.26 & 6.65 & 6.6 & 0.67 \\
\hline-1.86 & -0.51 & 3.33 & -2.07 & 0.22 \\
-6.15 & -6.98 & 14.39 & -12.52 & 20.94 \\
\hline
\end{tabular}

Panel B: Main Strategies

\begin{tabular}{|c|c|c|c|c|c|c|c|c|c|c|c|}
\hline CTA & $\mathrm{N}$ & Mean & Std & Sharpe & ES & MPPM & Alpha & $t$-stat & SystRisk & IdioRisk & $R^{2}$ \\
\hline ARU & 24 & -0.98 & 15.09 & -0.06 & 7.62 & -6.50 & -1.27 & -0.17 & 7.33 & 7.55 & 0.56 \\
\hline $\mathrm{HF}$ & 752 & 0.78 & 14.99 & 0.05 & 7.12 & -5.15 & -0.86 & -0.12 & 4.09 & 9.65 & 0.24 \\
\hline Difference & & -1.75 & 0.10 & -0.12 & 0.50 & -1.34 & -0.41 & -0.05 & 3.24 & -2.10 & 0.33 \\
\hline$t$-statistic & & -2.30 & 0.86 & -2.01 & 1.49 & -1.53 & -1.47 & -1.23 & 3.50 & -1.00 & 4.41 \\
\hline Emerging Markets & $\mathrm{N}$ & Mean & Std & Sharpe & ES & MPPM & Alpha & $t$-stat & SystRisk & IdioRisk & $R^{2}$ \\
\hline ARU & 77 & 1.79 & 22.26 & 0.09 & 11.48 & -10.52 & -0.35 & -0.06 & 13.87 & 7.30 & 0.82 \\
\hline $\mathrm{HF}$ & 1334 & 2.89 & 17.60 & 0.17 & 8.73 & -4.59 & 1.24 & 0.19 & 7.53 & 8.93 & 0.58 \\
\hline Difference & & -1.10 & 4.66 & -0.09 & 2.75 & -5.93 & -1.59 & -0.24 & 6.35 & -1.63 & 0.25 \\
\hline$t$-statistic & & -0.95 & 3.97 & -2.02 & 4.92 & -3.74 & -2.24 & -2.58 & 7.78 & -3.01 & 8.83 \\
\hline
\end{tabular}




\begin{tabular}{|c|c|c|c|c|c|c|c|c|c|c|c|}
\hline Global Macro & $\mathrm{N}$ & Mean & Std & Sharpe & ES & MPPM & Alpha & $t$-stat & SystRisk & IdioRisk & $R^{2}$ \\
\hline ARU & 36 & -0.12 & 11.94 & -0.05 & 6.42 & -3.91 & -1.45 & -0.36 & 6.84 & 5.12 & 0.71 \\
\hline $\mathrm{HF}$ & 443 & 1.46 & 14.09 & 0.12 & 7.18 & -3.75 & 0.09 & 0.01 & 4.95 & 7.11 & 0.46 \\
\hline Difference & & -1.58 & -2.15 & -0.17 & -0.76 & -0.15 & -1.54 & -0.37 & 1.89 & -1.99 & 0.25 \\
\hline$t$-statistic & & -2.13 & -2.19 & -1.77 & -1.05 & -0.09 & -2.12 & -2.51 & 1.51 & -5.25 & 4.67 \\
\hline Long Only & $\mathrm{N}$ & Mean & Std & Sharpe & ES & MPPM & Alpha & $t$-stat & SystRisk & IdioRisk & $R^{2}$ \\
\hline ARU & 80 & 4.84 & 18.45 & 0.29 & 9.27 & -4.02 & -1.38 & -0.20 & 12.49 & 5.36 & 0.87 \\
\hline $\mathrm{HF}$ & 288 & 6.75 & 17.19 & 0.47 & 8.00 & 0.36 & 1.64 & 0.29 & 8.91 & 6.35 & 0.77 \\
\hline Difference & & -1.91 & 1.26 & -0.18 & 1.27 & -4.38 & -3.01 & -0.49 & 3.58 & -0.99 & 0.10 \\
\hline$t$-statistic & & -2.72 & 1.29 & -4.02 & 2.34 & -3.47 & -4.02 & -4.17 & 4.07 & -2.56 & 5.30 \\
\hline Long/Short & $\mathrm{N}$ & Mean & Std & Sharpe & ES & MPPM & Alpha & $t$-stat & SystRisk & IdioRisk & $R^{2}$ \\
\hline ARU & 80 & 2.75 & 15.72 & 0.17 & 8.08 & -4.38 & 1.38 & 0.29 & 9.03 & 5.93 & 0.78 \\
\hline $\mathrm{HF}$ & 2136 & 4.71 & 14.91 & 0.36 & 7.03 & -0.79 & 0.78 & 0.14 & 6.47 & 7.38 & 0.59 \\
\hline Difference & & -1.96 & 0.81 & -0.18 & 1.05 & -3.58 & 0.59 & 0.15 & 2.56 & -1.44 & 0.19 \\
\hline$t$-statistic & & -2.80 & 1.69 & -3.90 & 3.26 & -3.51 & 0.67 & 0.59 & 5.21 & -3.52 & 6.79 \\
\hline Market Neutral & $\mathrm{N}$ & Mean & Std & Sharpe & ES & MPPM & Alpha & $t$-stat & SystRisk & IdioRisk & $R^{2}$ \\
\hline ARU & 27 & 0.55 & 12.91 & 0.05 & 4.79 & -3.63 & 1.63 & 0.35 & 7.69 & 4.63 & 0.79 \\
\hline $\mathrm{HF}$ & 346 & 3.07 & 10.13 & 0.33 & 6.45 & 0.59 & 1.77 & 0.33 & 2.51 & 6.04 & 0.30 \\
\hline Difference & & -2.52 & 2.78 & -0.28 & 1.66 & -4.22 & -0.14 & 0.02 & 5.18 & -1.41 & 0.49 \\
\hline$t$-statistic & & -2.85 & 2.31 & -3.39 & 3.16 & -3.54 & -0.66 & 0.75 & 4.18 & -1.92 & 5.48 \\
\hline Multi-Strategy & $\mathrm{N}$ & Mean & Std & Sharpe & ES & MPPM & Alpha & $t$-stat & SystRisk & IdioRisk & $R^{2}$ \\
\hline ARU & 33 & -0.97 & 13.97 & -0.10 & 7.26 & -5.70 & -0.42 & -0.15 & 7.50 & 5.76 & 0.77 \\
\hline $\mathrm{HF}$ & 1454 & 1.75 & 15.36 & 0.12 & 7.56 & -3.76 & -0.37 & -0.05 & 7.11 & 7.17 & 0.57 \\
\hline Difference & & -2.72 & -1.39 & -0.23 & -0.30 & -1.94 & -0.06 & $\begin{array}{l}-0.09 \\
\end{array}$ & 0.39 & -1.41 & 0.20 \\
\hline$t$-statistic & & -2.70 & -1.33 & -2.65 & -0.52 & -1.09 & -0.17 & -0.31 & 1.32 & -2.94 & 3.94 \\
\hline Relative Value & $\mathrm{N}$ & Mean & Std & Sharpe & ES & MPPM & Alpha & $t$-stat & SystRisk & IdioRisk & $R^{2}$ \\
\hline ARU & 71 & 1.29 & 12.67 & 0.09 & 6.83 & -2.45 & 1.40 & 0.36 & 7.98 & 4.44 & 0.82 \\
\hline $\mathrm{HF}$ & 830 & 5.53 & 9.39 & 0.64 & 4.23 & 2.98 & 3.06 & 0.73 & 2.80 & 4.97 & 0.40 \\
\hline Difference & & -4.24 & 3.28 & -0.55 & 2.60 & -5.43 & -1.66 & -0.36 & 5.19 & -0.53 & 0.42 \\
\hline$t$-statistic & & -5.44 & 4.21 & -6.84 & 5.55 & -6.46 & -1.94 & -2.31 & 7.50 & -2.12 & 9.05 \\
\hline
\end{tabular}




\section{Table B5: Performance Persistence at the Monthly Horizons}

For persistence testing, we perform equal-weighted sorts based on 24-month rolling alpha $t$-statistics. All sorts are based on USD returns of backfill- and size-adjusted funds. Bootstrapped spread and monotonicity tests are based on 5,000 Politis-Romano block bootstrap replications with an expected block length of six months. The replications are generated from the sorted portfolios using the same sample dates for each portfolio, and thus preserve the dependency structure between the portfolios.

Panel A: ARUs

\begin{tabular}{ccccccc} 
& Alpha & $t$-statistic & Appraisal & Sharpe & MPPM & ES \\
\hline Bottom & -1.78 & -1.06 & -0.36 & 0.20 & -2.61 & 9.34 \\
1 & -1.58 & -1.01 & -0.35 & 0.19 & -5.02 & 11.59 \\
2 & -1.41 & -0.87 & -0.30 & 0.22 & -4.29 & 11.81 \\
3 & -2.55 & -1.57 & -0.54 & 0.19 & -4.00 & 10.96 \\
Top & 0.39 & 0.24 & 0.08 & 0.30 & -1.47 & 10.33 \\
\hline Diff & 2.18 & 1.30 & 0.45 & 0.10 & 1.14 & 1.00 \\
tHAC & 0.93 & 0.91 & 0.91 & 0.60 & 0.38 & 0.55 \\
& & & & & & \\
\hline pMR_Up & 0.27 & 0.26 & 0.26 & 0.10 & 0.52 & 0.34 \\
pMR_Down & 0.70 & 0.63 & 0.63 & 0.51 & 0.51 & 0.86 \\
\hline
\end{tabular}

Panel B: Hedge Funds

\begin{tabular}{ccccccc} 
& Alpha & $t$-statistic & Appraisal & Sharpe & MPPM & ES \\
\hline Bottom & -2.50 & -2.36 & -0.81 & 0.07 & -1.86 & 6.77 \\
1 & -0.28 & -0.26 & -0.09 & 0.27 & 0.20 & 6.55 \\
2 & 1.66 & 1.51 & 0.52 & 0.45 & 1.96 & 5.51 \\
3 & 2.05 & 2.14 & 0.73 & 0.51 & 2.42 & 5.49 \\
Top & 3.41 & 3.96 & 1.36 & 0.76 & 3.88 & 4.41 \\
\hline Diff & 5.91 & 6.32 & 2.17 & 0.69 & 5.73 & -2.37 \\
tHAC & 6.89 & 6.23 & 6.23 & 3.79 & 3.65 & -5.97 \\
& & & & & & \\
\hline pMR_Up & 0.00 & 0.00 & 0.00 & 0.01 & 0.00 & 0.94 \\
pMR_Down & 0.99 & 0.96 & 0.96 & 0.96 & 0.98 & 0.00 \\
\hline
\end{tabular}


Panel C: Liquid Hedge Funds

\begin{tabular}{ccccccc} 
& Alpha & $t$-statistic & Appraisal & Sharpe & MPPM & ES \\
\hline Bottom & -3.89 & -2.98 & -1.02 & 0.05 & -3.67 & 8.89 \\
1 & -0.14 & -0.10 & -0.03 & 0.32 & 0.21 & 7.62 \\
2 & 2.81 & 1.63 & 0.56 & 0.44 & 1.59 & 7.37 \\
3 & 2.49 & 1.51 & 0.52 & 0.46 & 1.67 & 7.47 \\
Top & 1.83 & 1.10 & 0.38 & 0.36 & 0.32 & 8.35 \\
\hline Diff & 5.72 & 4.08 & 1.40 & 0.31 & 3.99 & -0.53 \\
tHAC & 3.26 & 3.13 & 3.13 & 1.86 & 1.96 & -0.39 \\
& & & & & & \\
\hline pMR_Up & 0.12 & 0.15 & 0.15 & 0.38 & 0.47 & 0.79 \\
pMR_Down & 0.98 & 0.99 & 0.99 & 0.93 & 0.99 & 0.60 \\
\hline
\end{tabular}




\section{Table B6: Performance Persistence at the Annual Horizons}

For persistence testing, we perform equal-weighted sorts based on 24-month rolling alpha $t$-statistics. All sorts are based on USD returns of backfill- and size-adjusted funds. Bootstrapped spread and monotonicity tests are based on 5,000 Politis-Romano block bootstrap replications with an expected block length of six months. The replications are generated from the sorted portfolios using the same sample dates for each portfolio, and thus preserve the dependency structure between the portfolios.

Panel A: ARUs

\begin{tabular}{ccccccc} 
& Alpha & $t$-statistic & Appraisal & Sharpe & MPPM & ES \\
\hline Bottom & 0.38 & 0.21 & 0.07 & 0.33 & -0.13 & 8.29 \\
1 & -3.16 & -1.95 & -0.67 & 0.11 & -5.98 & 11.36 \\
2 & -2.53 & -1.56 & -0.53 & 0.16 & -6.21 & 12.21 \\
3 & -2.98 & -1.84 & -0.63 & 0.15 & -6.46 & 12.26 \\
Top & 0.18 & 0.11 & 0.04 & 0.29 & -1.02 & 9.27 \\
\hline Diff & -0.20 & -0.10 & -0.03 & -0.04 & -0.89 & 0.98 \\
tHAC & -0.10 & -0.08 & -0.08 & -0.24 & -0.33 & 0.56 \\
& & & & & & \\
\hline pMR_Up & 0.68 & 0.63 & 0.63 & 0.70 & 0.64 & 0.83 \\
pMR_Down & 0.56 & 0.51 & 0.51 & 0.45 & 0.62 & 0.90 \\
\hline
\end{tabular}

Panel B: Hedge Funds

\begin{tabular}{ccccccc} 
& Alpha & $t$-statistic & Appraisal & Sharpe & MPPM & ES \\
\hline Bottom & -0.95 & -0.84 & -0.29 & 0.22 & -0.27 & 6.23 \\
1 & 1.02 & 1.02 & 0.35 & 0.40 & 1.52 & 6.11 \\
2 & 1.34 & 1.15 & 0.39 & 0.42 & 1.65 & 5.91 \\
3 & 1.07 & 1.04 & 0.36 & 0.41 & 1.64 & 5.51 \\
Top & 2.22 & 2.72 & 0.93 & 0.56 & 2.59 & 4.81 \\
\hline Diff & 3.17 & 3.56 & 1.22 & 0.33 & 2.86 & -1.42 \\
tHAC & 2.88 & 3.01 & 3.01 & 1.82 & 1.83 & -2.25 \\
& & & & & & \\
\hline pMR_Up & 0.22 & 0.19 & 0.19 & 0.14 & 0.09 & 0.92 \\
pMR_Down & 0.99 & 0.96 & 0.96 & 0.89 & 0.97 & 0.01 \\
\hline
\end{tabular}


Panel C: Liquid Hedge Funds

\begin{tabular}{ccccccc} 
& Alpha & $t$-statistic & Appraisal & Sharpe & MPPM & ES \\
\hline Bottom & -2.38 & -1.64 & -0.56 & 0.12 & -2.58 & 8.39 \\
1 & -0.35 & -0.24 & -0.08 & 0.30 & -0.08 & 7.77 \\
2 & 2.21 & 1.23 & 0.42 & 0.41 & 0.92 & 8.44 \\
3 & 0.62 & 0.33 & 0.11 & 0.33 & 0.16 & 7.94 \\
Top & 3.58 & 2.15 & 0.74 & 0.49 & 2.13 & 7.33 \\
\hline Diff & 5.95 & 3.79 & 1.30 & 0.37 & 4.71 & -1.07 \\
tHAC & 3.96 & 3.85 & 3.85 & 2.45 & 2.43 & -0.89 \\
& & & & & & 0.37 \\
pMR_Up & 0.33 & 0.32 & 0.32 & 0.20 & 0.11 & 0.35 \\
\hline pMR_Down & 0.79 & 0.75 & 0.75 & 0.65 & 0.73 & \\
\hline
\end{tabular}

